\title{
NUTRIÇÃO MINERAL DE HORTALIÇAS. XXIX. ABSORÇÃO DE MACRONUTRIENTES POR QUATRO CULTIVARES DE MORANGUEIRO (Fragaria spp.)*
}

\author{
Homenagem à Escola Superior de Agricultura "Luiz de Queiroz" \\ pelos seus 75 anos de existência.
}

\author{
Antonio Francisco Souza ** \\ HENRIQUE PAULO HAAG *** \\ José RENATO SARRUGE *** \\ Gilberto Diniz DE Oliveira *** \\ KEIGO MINAMI ****
}

\section{RESUMO}

Efetuou-se um estudo para avaliar a absorção e a extração dos macronutrientes nos seguintes cultivares de morangueiro: Campinas (IAC-2712) ; Camanducaia (IAC-3530); Monte Alegre (IAC3113) e SH-2 em condições de campo.

A instalação deu-se em um solo pertencente ao grande grupo Terra Roxa Estruturada, e à série "Luiz de Queiroz" cultivado intensivamente com hortaliças há mais de 25 anos, em Piracicaba-SP. A adubação aplicada foi uniforme para todos os cultivares. São apresentadas as concentrações dos macronutrientes em porcentagem nos seguintes órgãos: caules, folhas e frutos dos cultivares em função da idade (X) em dias.

Constatou-se que os cultivares diferem quanto à absorção dos macronutrientes ( $\mathrm{P}, \mathrm{K}, \mathrm{Ca}$ e $\mathrm{S}$ em relação a caules e folhas, e, $\mathrm{N}, \mathrm{P}, \mathrm{K}, \mathrm{Mg}$ e $\mathrm{S}$ em relação aos frutos).

Constatou-se também que os cultivares extraem totais diferentes de $\mathrm{P}, \mathrm{K}, \mathrm{Ca}, \mathrm{Mg}$ e $\mathrm{S}$ sendo as extracõos de $\mathrm{P}$ pelos cultivares menores do que as extrações de $\mathrm{Ca}$ e $\mathrm{Mg}$, e no global as de $\mathrm{Mg}$ são equivalentes às de $\mathrm{S}$.

As quantidades máximas extraídas pelos cultivares para uma população de 150.000 plantas/ha foram : $\mathrm{N}-192 \mathrm{~kg} ; \mathrm{P}-24-50 \mathrm{~kg}$; $\mathrm{K}-133-244 \mathrm{~kg} ; \mathrm{Ca}-76-116 \mathrm{~kg} ; \mathrm{Mg}-30-34 \mathrm{~kg} ; \mathrm{S}-13-27 \mathrm{~kg}$.

\footnotetext{
* Parte da dissertação apresentada pelo primeiro autor à Escola Superior de Agricultura "Luiz de Queiroz", USP para a obtenção do grau de Mestre em Solos e Nutrição de Plantas. Entregue para publicação em 30.12.1976.

** OEPAE/EMBRAPA, Brasalia, DF.

*** Departamento de Química, E.S.A. "Luiz de Queiroz", USP.

*** Departamento de Agricultura e Horticultura, E.S.A. "Luiz de Queiroz", USP.
} 


\section{INTRODUÇÃO}

Em nosso País, pouca ênfase tem sido dada a trabalhos específicos relacionados à nutrição mineral de morangueiro (Fragaria spp.) envolvendo aspectos como absorção, concentração e extração de macronutrientes como suporte básico a estudos de adubação do morangueiro no Brasil.

Recentemente, SOUZA (1976), estudou a absorção de todos os macronutrientes em quatro cultivares de morangueiro, constatando que esses cultivares não diferem quanto à absorção do $\mathrm{N}$ em relação a caules e folhas, mas sim em relação aos frutos.

Dos macronutrientes, o $\mathrm{N}$ e o $\mathrm{K}$, segundo BOYCE e MATLOCK (1966), são bastante contraditórios como assinalam estes autores. As divergências nos resultados são atribuídas entre outros, a fatores como clima, solo e cultivares como citam BOULD e CATLOW (1954).

Com relação a concentração do $\mathrm{N}$ nas folhas, JOHANSON e WALKER (1963) encontraram teores entre $1,31 \%$ e 2,24\% nos tratamentos com deficiência de $\mathrm{N}$ e completo, e com relação ao $\mathrm{P}$ e ao $\mathrm{K}$, HOLUBOWICZ (1969), menciona concentrações de $0,35 \%$ e $2,45 \%$, respectivamente, para $\mathrm{P}$ e $\mathrm{K}$ no estádio de florescimento, decrescendo na maturação. Segundo BOULD (1964) o teor adequado de P na floração deve ser maior do que $0,3 \%$ na floração.

Para o Ca, JOHANSON e WALKER (1963), citam como níveis normais e deficientes, valores de $0,38 \%$ e $1,9 \%$ nas folhas. Com relação ao $\mathrm{Mg}$, as exigências do morangueiro são baixas, segundo BOULD (1964), concentração menor do que $0,06 \%$, provoca sintomas de deficiência, e de $0,06 \%$ a $0,1 \%$ ocorre alta possibilidade de resposta à aplicação de $\mathrm{Mg}$. Dados sobre concentração de $\mathrm{S}$ em morangueiro são escassos; JOHN et alii (1975), menciona que a concentração desse nutriente nas folhas decresce rapidamente durante a floração $(0,18$ a $0,16 \%)$ e frutificação $(0,15$ a $0,12 \%)$.

Os valores sobre extração de nutrientes pelo morangueiro são raros, RAZUMNAYA (1973) estimou os seguintes parâmetros em $\mathrm{kg} / \mathrm{ha}$ para morangueiros com $2.500 \mathrm{~kg} / \mathrm{ha}: 47$ a $56 \mathrm{~kg}$ de $\mathrm{N} ; 9$ a $14 \mathrm{~kg}$ de $\mathrm{P}$ e 41 a 51 kgde $\mathrm{K}$.

\section{MATERIAL E MÉTODOS}

O experimento foi instalado em condições de campo, em um solo pertencente ao grande grupo Terra Roxa Estruturada (Comissão de Solos, 1960) e à série "Luiz de Queiroz" segundo RANZANI (1966), 
cabendo ressaltar que este solo vem sendo cultivado intensivamente há mais de 25 anos consecutivos e os resultados da análise química encontra-se na Tabela 1.

Tabela 1 - Determinações Químicas da Camada Arável do Solo.

\begin{tabular}{|c|c|c|c|c|c|c|c|c|}
\hline \multirow{2}{*}{$\begin{array}{l}\text { Amostras de solo nos } \\
\text { canteiros dos cultivares }\end{array}$} & \multirow{2}{*}{$\mathrm{pH}$} & \multicolumn{7}{|c|}{ Teor trocável em e.mg/100 g de T.S.F.A. } \\
\hline & & $\%$ & $\mathrm{PO}_{4}{ }^{3-}$ & $\mathrm{K}^{+}$ & $\mathrm{Ca}^{2+}$ & $\mathrm{Mg}^{2+}$ & $\mathrm{Al}^{3+}$ & $\mathrm{H}^{+}$ \\
\hline Campinas (IAC-2712) & 5,3 & 1,68 & 2,43 & 0,54 & 13,12 & 3,20 & 0,19 & 6,56 \\
\hline Camanducaia (IAC-3350) & 5,3 & 2,97 & 2,70 & 0,54 & 12,88 & 2,96 & 0,19 & 6,56 \\
\hline \multicolumn{9}{|l|}{ Monte Alegre } \\
\hline (IAC-3113) & 5,6 & 2,43 & 2,97 & 0,42 & 11,44 & 2,48 & 0,16 & 4,96 \\
\hline $\mathrm{SH}-2$ & 6,2 & 0,93 & 0,40 & 0,68 & 6,16 & 2,32 & 0,06 & 1,92 \\
\hline
\end{tabular}

Interpretação dos resultados analíticos segundo CATANI \& JACINTHO (1974) $=\mathrm{pH}$ - acidez média; carbono - alto; $\mathrm{PO}_{4}{ }^{3-}-$ alto; $\mathrm{K}^{+}-$alto; $\mathrm{Ca}^{2+}-$ alto; $\mathrm{Al}^{3+}$ trocável - baixo; $\mathrm{H}^{+}-$protons alto.

Utilizou-se mudas oriundas de estolhos dos cultivares Campinas (IAC-2712), Camanducaia (IAC-5330), Monte Alegre (IAC-3113) e SH-2, as quais foram enviveiradas previamente no estacamento de $25 \mathrm{~cm} \times 5 \mathrm{~cm}$, segundo as recomendações de CAMARGO (1973), e transplantadas após 30 dias ao local definitivo no espaçamento de $0,26 \mathrm{~m} \times 0,25 \mathrm{~m}$.

Os fertilizantes empregados foram: sulfato de amônio $(20 \% \mathrm{~N})$, superfosfato triplo $\left(20 \% \mathrm{P}_{2} \mathrm{O}_{5}\right)$ e cloreto de potássio $\left(60 \%\right.$ de $\left.\mathrm{K}_{2} \mathrm{O}\right)$ que foram aplicados no fundo do sulco nas seguintes quantidades:

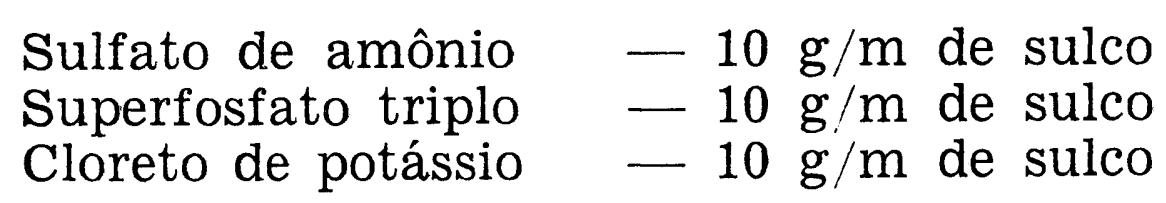

Trinta dias após o transplante efetuou-se uma aplicação em cobertura de $10 \mathrm{~g}$ de sulfato de amônio por planta.

As plantas para análise foramcoletadas ao acaso, tomando-se sempre em cada colheita, um total de 4 plantas, representando cada planta uma repetição. A primeira amostragem deu-se aos 76 dias após o transplante ao local definitivo no início da fase de floração, e as seguintes em períodos regulares de 20 e de 40 dias, com respeito a frutos, caules e folhas, respectivamente até redução acentuada da produção total de frutos.

Após cada coleta, as plantas foram lavadas com água destilada e em seguida com água desmineralizada e separada em caules (pecío- 
los + coroa), folhas e frutos; postos a secar em estufa de circulação de ar forçada à temperatura de $80^{\circ} \mathrm{C}$, e moídos em moinho do tipo semi-micro Willey e analisados quimicamente para $\mathrm{N}, \mathrm{P}, \mathrm{K}, \mathrm{Mg}$ e S, segundo os métodos descritos em SARRUGE e HAAG (1974).

O delineamento estatístico foi inteiramente casualizado, com 4 repetições (PIMENTEL GOMES, 1973), de modo que cultivares e épocas foram analisados conjuntamente segundo um esquema de "split-plot" onde os cultivares e as épocas foram colocados em parcelas e subparcelas, respectivamente.

Os dados foram analisados para:

- análise da variância conjunta referente às quantidades acumuladas (em g, mg e $\mu /$ gplanta, respectivamente) de matéria seca, $\mathrm{N}$, $\mathrm{P}, \mathrm{K}, \mathrm{Mg}$ e $\mathrm{S}$ das partes amostradas, respectivamente;

- ajustes de curvas de regressão para as quantidades acumuladas de matéria seca, $\mathrm{N}, \mathrm{P}, \mathrm{K}, \mathrm{Ca}, \mathrm{Mg}$ e $\mathrm{S}$, pelos órgãos dos cultivares em função de épocas, determinando-se ainda os respectivos pontos de máxima e de inflexão. A escolha das curvas recaiu sempre sobre aquela cujo componente mais elevado foi significativo ( $5 \%$ de probabilidade). Os pontos de máxima foram obtidos pela substituição das raízes da equação diferencial de $1 .^{\text {a }}$ ordem na equação principal, e os pontos de inflexão pela resolução da diferencial de $2 .^{a}$ ordem.

Em todos os casos em que a acumulação de matéria seca ou de nutrientes nos órgãos foi expressa por regressão linear, considerou-se como ponto de máxima, a última época em dias correspondente à maior quantidade acumulada.

\section{RESULTADOS E DISCUSSÃO}

\section{Crescimento}

O crescimento das plantas traduzido pela acumulação de matéria seca nos órgãos dos cultivares em função das diferentes épocas foi determinado em $\mathrm{g}$ dos órgãos/planta, e também estimado em $\mathrm{kg} / \mathrm{ha}$. Encontra-se expresso na Tabela 2.

A análise da variância conjunta (não incluída), permitiu concluir que os cultivares diferem na acumulação de matéria seca, tanto em relação a caules e folhas como em relação aos frutos.

A interação cultivares $\mathrm{x}$ épocas foi significativa indicando uma dependência entre cultivares e épocas de produção de matéria seca. Este fato permitiu o desdobramento através da análise de regressão 


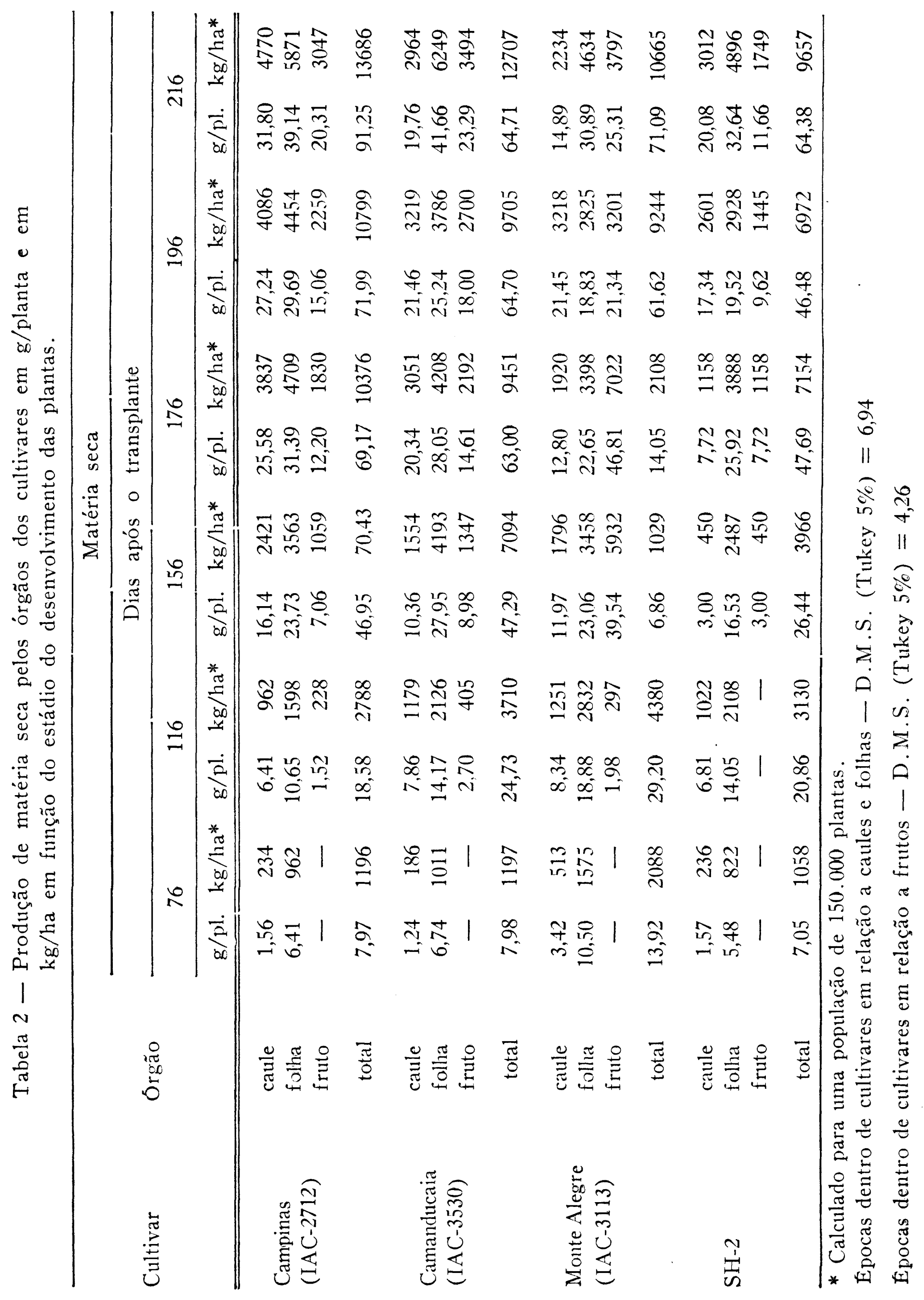


das diferentes épocas dentro de cada cultivar, o que possibilitou obter a expressão matemática do crescimento para os diferentes órgãos dos cultivares.

A análise de regressão, sugere que as curvas que descrevem a produção de matéria seca nos órgãos dos cultivares correspondem a regressões do $1 .^{\circ}, 2 .^{\circ}$ e $3 .{ }^{\circ}$ grau, como mostram os dados da Tabela 3.

Tabela 3 - Regressões representativas da acumulação de matéria seca nos órgãos dos cultivares, em $\mathrm{g} /$ planta ( $\hat{\mathrm{y}}$ ) em função da idade $(\mathrm{X})$ em dias após o transplante.

\begin{tabular}{llc}
\hline & \multicolumn{1}{c}{ Mquacéria seca } & \\
\cline { 2 - 4 } Cultivar & Orgão de regressão & $\begin{array}{c}\text { Coeficiente } \\
\text { de } \\
\text { determi- } \\
\text { nação }\left(\mathrm{r}^{2}\right)\end{array}$ \\
\hline Campinas & caule $\hat{\mathrm{y}}=-16,672+0,216 \mathrm{X}$ & 0,97 \\
(IAC-2712) & folla $\hat{\mathrm{y}}=-10,578+0,207 \mathrm{X}$ & 0,96 \\
& fruto $\hat{\mathrm{y}}=-26,007+0,213 \mathrm{X}$ & 0,48 \\
Camanducaia & caule $\hat{\mathrm{y}}=-11,232+0,157 \mathrm{X}$ & 0,93 \\
(IAC-3530) & folha $\hat{\mathrm{y}}=91,937+2,502 \mathrm{X}+22,690.10^{-3} \mathrm{X}^{2}-59,501.10^{-6} \mathrm{X}^{3}$ & 0,99 \\
& fruto $\hat{\mathrm{y}}=-26,897+0,231 \mathrm{X}$ & 0,99 \\
Monte Alegre & caule $\hat{\mathrm{y}}=8,317+0,144 \mathrm{X}$ & 0,95 \\
(IAC-3113) & folha $\hat{\mathrm{y}}=-24,618+0,609 \mathrm{X}-19,719.10^{-4} \mathrm{X}^{2}$ & 0,98 \\
& fruto $\hat{\mathrm{y}}=-0,620+0,362 \mathrm{X}$ & 0,97 \\
& caule $\hat{\mathrm{y}}=-0,796+0,118 \mathrm{X}$ & 0,85 \\
SH-2 & follha $\hat{\mathrm{y}}=-1,276+0,111 \mathrm{X}$ & 0,90 \\
& fruto $\hat{\mathrm{y}}=-0,179+0,139 \mathrm{X}$ & 0,94 \\
\hline
\end{tabular}

A acumulação de matéria seca nos caules e nos frutos em todos os cultivares foi linear. Este fenômeno pode ser explicado como sendo devido à translocação de compostos fotossintetizados ao nível das folhas para serem acumulados nos caules e nos frutos. Este fenômeno foi também constatado por HAAG et alii (1973), em dois cultivares de maracujá, Passiflora edulis, Sims e Passiflora edulis f. flavicarpa, Deneger, "amarelo" e "roxo" na faixa entre 280 e 370 dias, e por THOMAZ (1975) na cultura do espinafre, Tetragon expansa, Murr. na faixa entre 45 a 120 dias.

Nos cultivares de morangueiro, a maior produção de matéria seca pelos caules situa-se na faixa que vai dos 76 aos 116 dias, e para os frutos dos 116 aos 156 dias. A produção de matéria seca pelas folhas, Tabela 3, nos cultivares Campinas (IAC-2712), Monte Alegre (IAC-3113), comportou-se seguindo regressões do $2 .^{\circ}$ e $3 .^{\circ}$ graus, enquan to se observou uma tendência a forma signóide no cultivar Camanducaia (IAC- 
3530). Este fenômeno foi também constatado por BRADFIELD (1970), em três cultivares de morangueiro, quando afirma que $75 \%$ da matéria seca total foi produzida em 8 meses, na faixa compreendida entre o florescimento e a colheita, que de certa forma concorda com os resultados obtidos no presente trabalho.

Um ligeiro decréscimo no ritmo de crescimento das folhas com redução no seu peso de matéria seca foi observada nos cultivares Camanducaia (IAC-3530) e Monte Alegre (IAC-3113), entre os 156 e os 196 dias, e pode ser explicado como sendo devido a uma maior translocação dos carboidratos e outros compostos ftossintetizados nas folhas, para os frutos, resultando em conseqüência uma maior produção de matéria seca por esses órgãos, como pode ser visto pelas quantidades máximas acumulades por esses cultivares nos frutos, uma vez que o morangueiro não apresenta grandes perdas de folhas, provocando uma redução acentuada no peso da matéria seca à medida que se aproxima o final do ciclo.

Fenômeno semelhante ocorre em outras culturas como: o quiabo, cravo, algodão, espinafre, milho e batatinha conforme mencionam COSTA et alii (1972), FERNANDES et alii (1972), SARRUGE et alii (1963), THOMAZ (1975), ANDRADE (1975) e MACEDO (1976). Os cultivares Campinas (IAC-2712) e SH-2 mostraram uma acumulação linear em todas as idades de desenvolvimento.

A produção máxima de matéria seca nos órgãos, assim como aquela quantidade que corresponde à época em que a taxa de produção de matéria seca é máxima, são apresentados em seguida, na Tabela 4.

Tabela 4 - Valores do ponto de máxima em dias, quantidade máxima em g de matéria seca nos órgãos por planta e ponto de inflexão em dias.

Cultivar

Ponto de Máxima Quantidade Máximá Ponto de Inflexão (dias) (g/planta) (dias)

caule folha fruto caule folha fruto Total caule folha fruto

\begin{tabular}{|c|c|c|c|c|c|c|c|c|c|c|}
\hline Campinas (IAC-2712) & 196 & 196 & 216 & 25 & 30 & 20 & 75 & - & - & 一 \\
\hline Camanducaia (IAC-3530) & 196 & 173 & 216 & 19 & 30 & 23 & 72 & 一 & 127 & 一 \\
\hline \multirow[t]{2}{*}{ Monte Alegre (IAC-3113) } & 196 & 154 & 216 & 19 & 22 & 26 & 67 & - & - & 一 \\
\hline & 196 & 196 & 216 & 15 & 20 & 12 & 47 & - & - & 一 \\
\hline
\end{tabular}

De acordo com os dados da Tabela 4, verificou-se que todos os cultivares atingiram o ponto de máxima em relação a caules aos 196 dias, com produção máxima variando entre 15 e $25 \mathrm{~g}$ de matéria seca, destacando-se entre os demais o cultivar Campinas (IAC-2712).

A produção máxima de matéria seca pelas folhas entre os cultivares variou entre 20 e $30 \mathrm{~g}$, sendo o cultivar Monte Alegre (IAC-3113) o mais: 
precoce atingindo o ponto de máxima aos 154 dias enquanto o cultivar Camanducaia (IAC-3530) o excedeu em 19 dias; quanto à sua maturação pode ser considerado como intermediário, já que os cultivares mais tardios atingiram o ponto de máxima aos 196 dias, este cultivar apresentou sua maior taxa de acumulação aos 127 dias, enquanto os demais teoricamente não o apresentaram.

Em relação aos frutos, as quantidades máximas acumuladas pelos diversos cultivares estão variando entre 12 a $26 \mathrm{~g}$ de matéria seca, sendo que a menor quantidade foi produzida pelo cultivar SH-2, atingindo todos os cultivares o ponto de máxima aos 216 dias.

Os cultivares que mais acumularam matéria seca tanto nos órgãos separadamente como na planta inteira, foram Campinas (IAC-2712) e Camanducaia (IAC-3530). A menor acumulação coube ao cultivar SH-2.

A água, um dos fatores limitantes do crescimento e conseqüentemente da produção de matéria seca, representada pelas chuvas, mostrou uma distribuição um tanto irregular no período compreendido entre maio e agosto de 1975. Os extremos de precipitações pluviométricas nesse período foram $0 \mathrm{~mm}$ e $11,3 \mathrm{~mm}$ e durante o período de execução do experimento variou entre $11,3 \mathrm{~mm}$ e $98 \mathrm{~mm}$. Essa irregularidade na distribuição das chuvas coincidiu também com os estádios de floração e frutificação, porém, a deficiência hídrica foi corrigida através de irrigações por infiltração, procurando-se assim manter o solo ao nível da capacidade de campo, a fim de que o crescimento das plantas não fosse comprometido.

MEYER et alii (1970), mencionaram que para a maioria das espécies vegetais, um teor de umidade no solo, próximo da capacidade de campo, é o mais favorável para o crescimento.

BRADFIELD (1970), trabalhando em condições de solução nutritiva, menciona taxas máximas de acumulação de matéria seca total no morangueiro, variando entre 0,23 e $0,47 \mathrm{~g} /$ dia entre os cultivares sob um suprimento de água de $390 \mathrm{ml} /$ dia.

As quantidades máximas totais de matéria seca em $\mathrm{g} / \mathrm{dia}$ produzidas pelos cultivares estudados variaram entre 0,33 e $0,53 \mathrm{~g} /$ dia concordando com aqueles encontrados por BRADFIELD (1970).

\section{Macronutrientes}

\section{Nitrogênio}

Os valores da concentração e as quantidades de $\mathrm{N}$ nos órgãos dos cultivares acham-se expressos na Tabela 5 . 


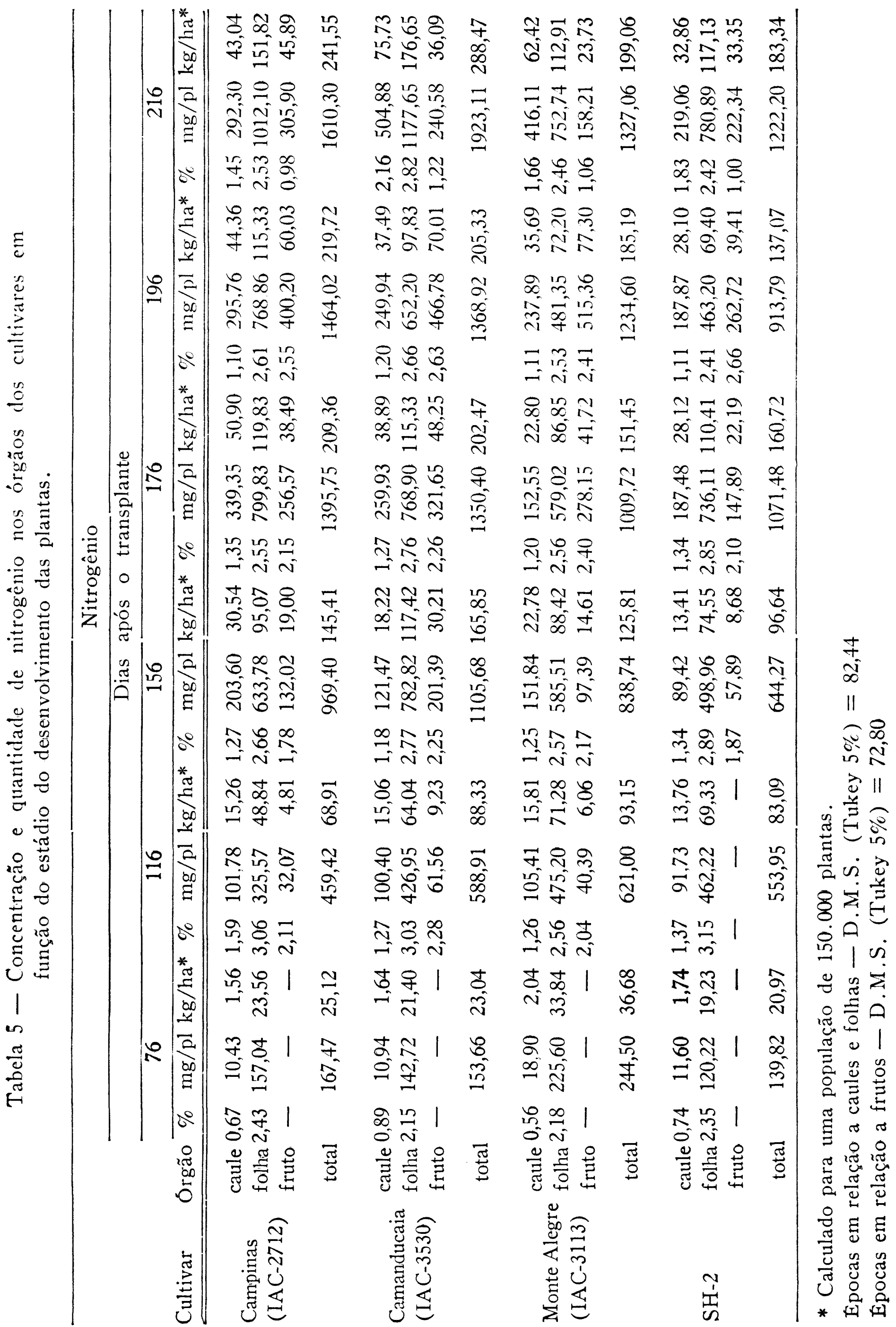


Segundo os resultados da análise da variância conjunta (não incluída), os cultivares não diferem na absorção de $\mathrm{N}$ em relação a caules e folhas, porém, diferem em relação aos frutos.

A interação cultivares $\mathrm{x}$ épocas não é significativa para absorção do $\mathrm{N}$, tanto em relação a caules e folhas como em relação aos frutos. Em vista disso, ajustou-se apenas uma equação de regressão expressando a absorção média por órgão para todos os cultivares, como mostram os dados da Tabela 6 .

Tabela 6 - Regressões representativas da absorção média de nitrogênio pelos órgãos dos cultivares em mg/planta ( $\hat{y}$ ) em função da idade $(X)$ em dias após o transplante.

\begin{tabular}{cccc}
\hline \multirow{2}{*}{ Cultivar* } & Órgão & Equação de regressão & Nitrogênio \\
\cline { 3 - 4 } & caule & $\hat{\mathrm{y}}=-124,387+1,828 \mathrm{X}$ & $\begin{array}{c}\text { Coeficiente } \\
\text { de determi- } \\
\text { nação }\left(\mathrm{r}^{2}\right)\end{array}$ \\
\hline folha & $\hat{\mathrm{y}}=-811,309+16,190 \mathrm{X}-45,853.10^{-3} \mathrm{X}^{2}$ & 0,98 \\
fruto & $\hat{\mathrm{y}}=-620,447+4,871 \mathrm{X}$ & 0,98 \\
\end{tabular}

* Os cultivares não diferem estatisticamente pelo teste $\mathrm{F}$ a $5 \%$ de probabilidade e foram discutidos em conjunto.

A análise da regressão mostrou também que as curvas que descrevem a acumulação do $\mathrm{N}$ em $\mathrm{mg}$, nos órgãos correspondem a regressões do $10^{\circ}$ e $2 .^{\circ}$ grau, como mostra a Tabela 6 .

A quantidade máxima extraída do nutriente e a época em que a planta apresenta essa quantidade nos órgãos é apresentada na Tabela 7.

Tabela 7 - Valores de ponto de máxima em dias e quantidade máxima em $\mathrm{mg}$ de $\mathrm{N}$ nos órgãos por planta.

\begin{tabular}{lcc} 
Orgão & $\begin{array}{c}\text { Ponto de Máxima } \\
(\text { dias })\end{array}$ & $\begin{array}{c}\text { Quantidade máxima } \\
(\mathrm{mg} / \text { planta })\end{array}$ \\
\hline Caules & 196 & 254 \\
Folhas & 176 & 616 \\
Frutos & 216 & 431 \\
\hline
\end{tabular}


Como as equações são do $1 .^{\circ}$ e do $2 .^{\circ}$ grau, elas não possuem ponto de inflexão, e, teoricamente os órgãos não apresentam uma época de exigência máxima, pois, o $\mathrm{N}$ foi absorvido durante todo o ciclo de desenvolvimento das plantas.

Das quantidades máximas de $\mathrm{N}$ contidas nos órgãos, a maior foi nas folhas com $616 \mathrm{mg}$, vindo em ordem decrescente os frutos com $431 \mathrm{mg}$, e os caules com $234 \mathrm{mg}$ de $\mathrm{N}$.

As extrações de $\mathrm{N}$ em $\mathrm{kg} / \mathrm{ha}$ pelos órgãos, foram as seguintes, para caules: $35 \mathrm{~kg} / \mathrm{ha}$; para folhas: $92 \mathrm{~kg} / \mathrm{ha}$ e para os frutos: $65 \mathrm{~kg} / \mathrm{ha}$.

Os dados de literatura concernentes à extração desse nutriente pelo morangueiro, são escassos, sendo todavia mais freqüente os relativos à concentração. RAZUMNAYA (1973), encontrou valores de extração de $\mathrm{N}$ em morangueiro de 2 anos de idade variando entre 47 e $56 \mathrm{~kg}$ de $\mathrm{N} / \mathrm{ha}$.

A distribuição porcentual do $\mathrm{N}$ nos órgãos, em ordem decrescente, foi a seguinte: folhas, frutos e caules (Tabela 5). Nas folhas, os teores altos foram verificados na faixa que se estende dos 76 aos 116 dias, variando entre 2,15 e $3,15 \%$, e decresce moderadamente no período que vai dos 156 aos 216 dias de 2,88 para $2,42 \%$, à medida que os cutivares intensificam a frutificação, o que evidencia uma translocação do nutriente das folhas para os frutos. Uma maior estabilidade da concentração nas folhas, como mostram os dados da Tabela 5, aparece entre os 156 e os 176 dias. A partir dos 176 dias, à proporção que as plantas amadurecem, esta mesma tendência se observa com relação aos caules.

Long e Murineek (1937), mencionados por LINEBERRY et alii (194:3), constataram que o conteúdo de $\mathrm{N}$ nas folhas, decresceu rapidamente durante a senescência com um simultâneo aumento desse nutriente nas raízes e nos caules, informaram ainda que as raízes acumularam 30 a $40 \%$ da quantidade total de $\mathrm{N}$ da planta durante $\mathrm{o}$ inverno.

Em condições de solução nutritiva, JOHANSON \& WALKER (1963), encontraram nas folhas, para os tratamentos completo e com omissão de $\mathrm{N}$, concentrações de 2,24 e $1,31 \%$. JOHN et alii (1975), estudando a influência de épocas sobre a composição de folhas e pecíolos em três cultivares de morangueiro em condições de campo, constataram efeito significativo de cultivares sobre a concentração dos nutrientes $\mathrm{N}, \mathrm{K}$, $\mathrm{Mg}, \mathrm{B}, \mathrm{Fe}, \mathrm{Mn}$ e $\mathrm{Zn}$ nas folhas, e $\mathrm{P}$ em relação aos pecíolos, assinalam também que a concentração do $\mathrm{N}$ particularmente nas folhas, decresceu até o final da frutificação. Constata-se ainda, pelos dados do autor, que o período de maior exigência do $\mathrm{N}$, ocorreu na fase inicial do crescimento até o início do florescimento, onde as concentrações registradas foram 4,15 e $3,58 \%$ respectivamente, decrescendo de 3,19 a $2,45 \%$ da frutificação até o final do ciclo. 
Os valores porcentuais de $\mathbf{N}$, obtidos no presente trabalho, concordam com os valores encontrados na literatura, desde que se levem em conta os limites impostos pelas condições de clima, solo, adubação e cultivares empregados.

Como sugestão ao estudo da diagnose foliar no morangueiro, são apresentadas as variações na concentração de $\mathrm{N}$ em caules $(0,56$ a $1,59 \%)$ e folhas $(2,15$ a $3,15 \%)$ correspondente às épocas em que as taxas de acumulação do nutriente foram mais altas, indo dos 76 aos 116 dias.

A variação de concentração de $\mathrm{N}$ nas folhas concordam com os valores críticos mencionados por BOULD (1964), no estádio de florescimento, onde os extremos 2,15 e $3,15 \%$ são considerados respectivamente deficientes e adequados, mas se tomarmos a média dos extremos $2,65 \%$, então a concentração de $\mathrm{N}$ nas folhas situa-se na faixa que $\mathrm{o}$ autor denomina de marginal, o que corresponderia a dizer-se que a planta está no limiar do seu estado nutricional ótimo.

A título de informação, segundo BOULD (1964), a concentração de $\mathrm{N} \%$ expressa na matéria seca de folhas recentemente maduras de morangueiros no estádio de florescimento apresentam os seguintes valores: deficiente $<2,5 \%$; marginal $2,6-2,9 \%$ e adequado $>3,0 \%$.

\section{Fósforo}

Os valores de concentração e as quantidades de $\mathrm{P}$ nos órgãos dos cultivares, acham-se expressos na Tabela 8.

A análise da variância conjunta (não incluída) revela que os cultivares diferiram na absorção de $\mathrm{P}$, em relação a caules, folhas e frutos.

A interação de cultivares $\mathrm{x}$ época foi significativa em relação a caules e folhas, em vista disso, procedeu-se o desdobramento através das análises de regressão das diferentes épocas dentro de cada cultivar, revelando a análise de regressão que as curvas que descrevem a absorção do nutrinte nesses órgãos correspondem a equações do $1 .^{\circ}$ e do $2 .^{\circ}$ graus, como mostram os dados da Tabela 9.

A interação de cultivares $x$ épocas em relação aos frutos não foi significativa, mostrando que os cultivares, não dependem de épocas para acumular o nutriente nos frutos, mas o fazem durante todo o período de frutificação em quantidades distintas, embora não sejam significativas. Em vista disso, ajustou-se apenas uma equação de regressão expressando assim a absorção média de $\mathrm{P}$ nos frutos para todos os cultivares.

Todos os cultivares comportaram-se linearmente na absorção do $\mathbf{P}$ pelos caules, seguindo a mesma tendência desse órgão na absorção do 


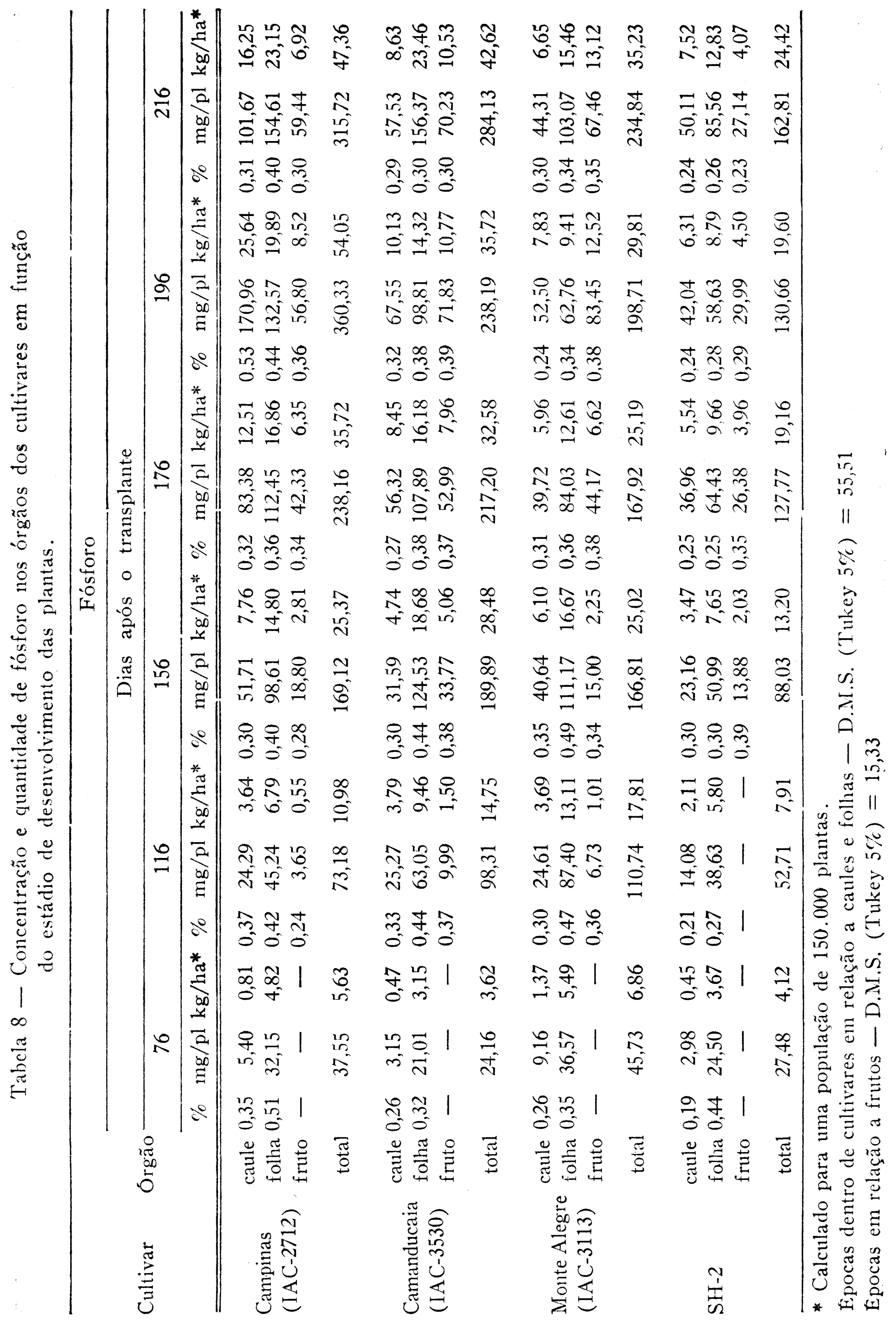


N e na produção de matéria seca. A acumulação pelas folhas nos cultivares Campinas (IAC-2712), Camanducaia (IAC-3530) e SH-2 seguiu equações do $1 .^{\circ}$ grau, enquanto que a absorção do cultivar Monte Alegre (IAC-3113) foi do $2 .^{\circ}$ grau (Tabela 9).

Tabela 9 - Regressões representativas da absorção de fósforo pelos órgãos dos cultivares em $\mathrm{mg} /$ planta $(\hat{\mathrm{y}})$ em função da idade $(\mathrm{X})$ em dias após o transplante.

\begin{tabular}{llcc}
\hline & \multicolumn{1}{c}{ Fósforo } & \\
\cline { 2 - 4 } Cultivar & Orgão & Equação de regressão & $\begin{array}{c}\text { Coeficiente } \\
\text { de determi- } \\
\text { nação (r') }\end{array}$ \\
\hline Campinas & caule & $\hat{\mathrm{y}}=115,106+1,311 \mathrm{X}$ & 0,82 \\
(IAC-2712) & folla & $\hat{\mathrm{y}}=-43,440+0,887 \mathrm{X}$ & 0,95 \\
& fruto & $\hat{\mathrm{y}}=-523,263+5,482 \mathrm{X}-12,840.10^{-3} \mathrm{X}^{2}$ & 0,98 \\
Camanducaia & faule & $\hat{\mathrm{y}}=-35,946+0,498 \mathrm{X}$ & 0,92 \\
(IAC-3530) & folha & $\hat{\mathrm{y}}=-23,407+0,731 \mathrm{X}$ & 0,71 \\
& fruto & $\hat{\mathrm{y}}=-523,263+5,482 \mathrm{X}-12,840.10^{-3} \mathrm{X}^{2}$ & 0,98 \\
Monte Alegre & caule & $\hat{\mathrm{y}}=-17,937+0,365 \mathrm{X}$ & 0,99 \\
(IAC-3113) & folha & $\hat{\mathrm{y}}=-216,086+4,473 \mathrm{X}-15,505.10^{-3} \mathrm{X}^{2}$ & 0,96 \\
& fruto & $\hat{\mathrm{y}}=-523,263+5,482 \mathrm{X}-12,840.10^{-2} \mathrm{X}^{3}$ & 0,98 \\
& & & 0,97 \\
SH-2 & caule & $\hat{\mathrm{y}}=-23,370+0,315 \mathrm{X}$ & 0,98 \\
& folha & $\hat{\mathrm{y}}=4,166+0,286 \mathrm{X}$ & 0,98 \\
\hline
\end{tabular}

Com relação a absorção do $\mathrm{P}$ pelos frutos, todos os cultivares comportaram-se seguindo uma equação do $2 .^{\circ}$ grau (Tabela 9).

O ponto no qual os cultivares atingiram a extração máxima do nutriente nos órgảos são mostrados na Tabela 10).

Os cultivares não apresentaram ponto de inflexão.

Examinando-se os dados, verifica-se que a extração máxima do $\mathrm{P}$ pelos caules entre os cultivares, está variando entre 39 e $141 \mathrm{mg}$ do nutriente, sendo que a maior extração foi realizada pelo cultivar Campinas (IAC-2712) e a menor pelo cultivar SH-2. Todos os cultivares atingiram o ponto de máximo aos 196 dias.

As quantidades máximas extraídas pelas folhas estão variando entre 60 e $130 \mathrm{mg}$ de $\mathrm{P}$, destacando-se o cultivar Campinas (IAC-2712) pela maior quantidade de $\mathrm{P}$ extraída, enquanto a menor extração coube ao cultivar SH-2. O ponto de máxima para os cultivares está variando 
Tabela 10 - Valores do ponto de máxima, em dias, e quantidade máxima de $\mathrm{P}$ extraída, em $\mathrm{mg}$, nos órgãos por planta.

\begin{tabular}{|c|c|c|c|c|c|c|c|}
\hline \multirow{2}{*}{ Cultivar } & \multicolumn{3}{|c|}{$\begin{array}{l}\text { Ponto de máxima } \\
\text { (dias) }\end{array}$} & \multicolumn{3}{|c|}{$\begin{array}{l}\text { Quantidade máxima } \\
\text { (mg/planta) }\end{array}$} & \multirow{2}{*}{ Total } \\
\hline & caule & folha & fruto & caule & folha & fruto & \\
\hline $\begin{array}{l}\text { Campinas } \\
\text { (IAC-2712) }\end{array}$ & 196 & 196 & 213 & 141 & 130 & 61 & 332 \\
\hline $\begin{array}{l}\text { Camanducaia } \\
\text { (IAC-3530) }\end{array}$ & 196 & 196 & 213 & 61 & 120 & 61 & 242 \\
\hline $\begin{array}{l}\text { Monte Alegre } \\
\text { (IAC-3113) }\end{array}$ & 196 & 194 & 213 & 53 & 106 & 61 & 220 \\
\hline $\mathrm{SH}-2$ & 196 & 196 & 213 & 39 & 60 & 61 & 160 \\
\hline
\end{tabular}

entre 194 e 196 dias, sendo o cultivar Monte Alegre (IAC-3113) o mais precoce e os demais tardios.

A extração máxima do nutriente pelos frutos em todos os cultivares foi de $61 \mathrm{mg}$ de $\mathrm{P}$, os cultivares são idênticos, atingindo o ponto de extração máxima aos 213 dias.

Em vista dos cultivares não apresentarem uma época de maior exigência (ponto de inflexão) na absorção do $P$, sendo este nutriente absorvido durante todo o ciclo da cultura, sugere-se que as recomendações na aplicação do fertilizante fosfatado seja de imediato o mais solúvel possível, encontrando-se à disposição das plantas desde o início do plantio.

As extrações de $\mathrm{P}$ em $\mathrm{kg} / \mathrm{ha}$ pelos órgãos dos cultivares foram as seguintes: caules - 6 a $21 \mathrm{~kg}$; folhas - 9 a $20 \mathrm{~kg}$ e frutos $9 \mathrm{~kg}$.

Esses resultados estão de acordo com as estimativas de 9 e $14 \mathrm{~kg}$ de $\mathrm{P} /$ ha mencionado por RZUMNAYA (1973).

$\mathrm{Na}$ extração total do nutriente, destacou-se o cultivar Campinas (IAC-2712) com uma extração de $50 \mathrm{~kg}$, e a menor verificou-se no cultivar SH-2 com $24 \mathrm{~kg}$.

Observando-se os dados da Tabela 8, verifica-se que os valores porcentuais do nutriente de uma maneira geral, cresceram do início do florescimento aos 76 dias, até aos 196 dias, que já corresponde à faixa de intensa frutificação e maturação, caindo moderadamente a concentração nos caules, e também nos frutos, na faixa que vai dos 
196 dias aos 216 dias, que já passa a coincidir com a maturação da cultura.

Nas folhas, a concentração do nutriente oscila entre 0,32 e $0,51 \%$ na floração, aos 76 dias e em duas épocas distintas quando as concentrações foram mais baixas na frutificação com oscilações entre $0,25 \mathrm{e}$ $0,36 \%$ aos 176 dias e 0,26 a $0,40 \%$ aos 216 dias. Estes resultados estão de acordo com os níveis críticos de $\mathrm{P}$ nas folhas segundo BOULD (1964), respectivamente nos estádios de floração e frutificação. Segundo esse autor, morangueiros que apresentaram $0,3 \%$ de $\mathrm{P}$ nas folhas atingiram o estádio de frutificação mais cedo percebendo ainda que concentrações de $\mathrm{P}$ inferiores a $0,2 \%$ nas folhas no estádio de frutificação, a produção foi severamente reduzida, não se registrando porém, sintomas de deficiência nas folhas até que fosse registrado uma concentração de $\mathbf{P}$ inferior a $0,1 \%$ nesses órgãos. Estes resultados também concordam com os valores porcentuais para o P nas folhas mencionados por JOHN (1975) quando citam valores de $0,35 \%$ do nutriente na floração e $0,29 \%$ na frutificação.

Como indicação para diagnose foliar são apresentadas as concentrações de $\mathrm{P}$ para caules e folhas aos 76 e aos 166 dias após o transplante, que corresponde às épocas onde as taxas de absorção nesses órgãos foram mais elevadas.

As faixas de concentração foram:

$$
\begin{aligned}
& \text { Caule: } \quad 0,35 \%-0,19 \% \text { a } 0,37 \%-0,21 \% \\
& \text { Folha: } \quad 0,51 \%-0,32 \% \text { a } 0,47 \%-0,27 \%
\end{aligned}
$$

\section{Potássio}

Os valores da concentração e as quantidades de $\mathrm{K}$ nos órgãos dos cultivares acham-se expressos na Tabela 11.

As análises da variância conjunta, das partes vegetativas e reprodutivas (não incluída), apresentaram os seguintes resultados:

A interação cultivares $x$ épocas foi significativa mostrando que existe uma dependência entre cultivares e épocas de absorção do $\mathbf{K}$.

O desdobramento através das análises de regressão correspondente às diferentes épocas dentro de cada cultivar, possibilitou o ajuste de regressões do $1 .^{\circ}$ e do $2 .^{\circ}$ graus, como são mostrados na Tabela 12.

Pelas equações de regressão correspondentes à absorção do $\mathrm{K}$ nos caules em todos os cultivares, verifica-se que estes órgãos seguem regressões lineares, revelando ainda que a absorção do nutriente se processou sem interrupção até a última época de amostragem, e até certo ponto atingindo níveis de luxo, refletindo a disponibilidade desse 


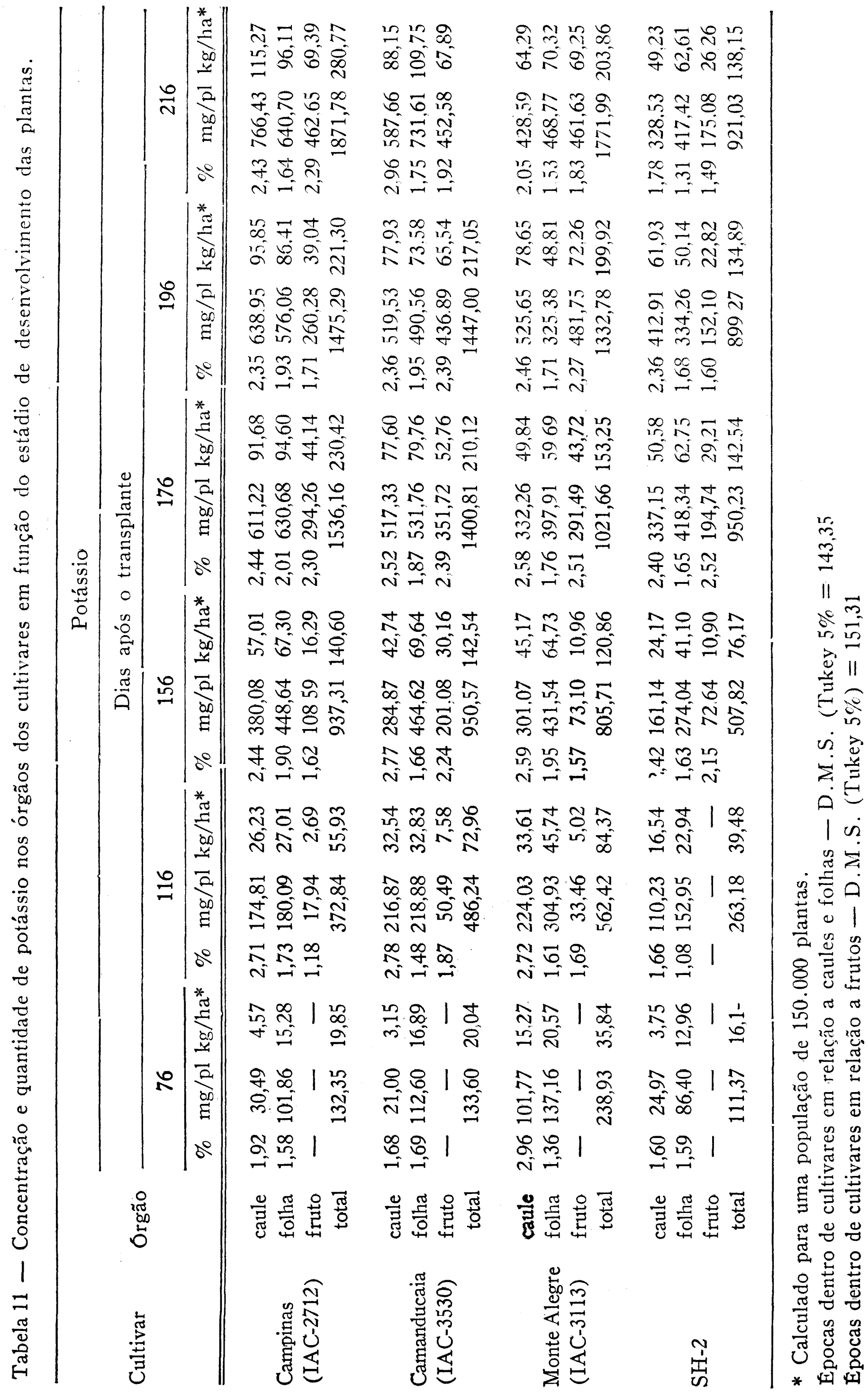


Tabela 12 - Regressões representativas da absorção de potássio pelos órgãos dos cultivares em $\mathrm{mg} /$ planta $(\hat{y})$ em função da idade $(X)$ em dias após o transplante.

Potássio

\begin{tabular}{llcc} 
Cultivar & Orgão & Equação de regressão & $\begin{array}{c}\text { Coeficiente } \\
\text { de determi- } \\
\text { nação }\left(\mathrm{r}^{2}\right)\end{array}$ \\
\hline \hline Campinas & caule & $\hat{\mathbf{y}}=-384,359+5,076 \mathrm{X}$ & 0,98 \\
(IAC-2712) & folha & $\begin{array}{l}\hat{\mathbf{y}}=-248,337+4,228 \mathrm{X} \\
\hat{\mathbf{y}}=-674,786+5,142 \mathrm{X}\end{array}$ & 0,95 \\
& fruto & & 0,83 \\
Camanducaia & caule & $\hat{\mathbf{y}}=-271,063+9,910 \mathrm{X}$ & 0,96 \\
(IAC-3530) & folha & $\hat{\mathbf{y}}=-147,410+3,450 \mathrm{X}$ & 0,92 \\
& fruto & $\hat{\mathbf{y}}=-420,335+4,199 \mathrm{X}$ & 0,88 \\
Monte Alegre & caule & $\hat{\mathbf{y}}=-170,418+3,371 \mathrm{X}$ & 0,95 \\
(IAC-3113) & folha & $\hat{\mathbf{y}}=-641,312+13,360 \mathrm{X}-42,800.10^{-3} \mathrm{X}^{2}$ & 0,95 \\
& fruto & $\hat{\mathbf{y}}=-6016,727+62,235 \mathrm{X}-14,907.10^{-3} \mathrm{X}^{2}$ & 0,98 \\
& & & 0,88 \\
SH-2 & caule & $\hat{\mathbf{y}}=-235,689+3,037 \mathrm{X}$ & 0,98 \\
& folha & $\hat{\mathbf{y}}=-82,078+2,161 \mathrm{X}$ & $(0,40)$ \\
& fruto & $\hat{\mathbf{y}}=-97,518+1,323 \mathrm{X}$ & \\
\hline
\end{tabular}

nutriente no solo. Na absorção por folhas e frutos, verificou-se, pela Tabela 12, que estes órgãos absorvem o $\mathrm{K}$ seguindo um comportamento retilíneo e curvilíneo. THOMAZ (1975), constatou que a absorção do $\mathrm{K}$ por frutos, caules e folhas pelo espinafre, comportou-se seguindo regressão do $1 .^{\circ}, 2 .^{\circ}$ e $3 .^{\circ}$ graus.

A quantidade máxima extraída do nutriente e as épocas são apresentadas na Tabela 13.

Como as equações que expressam absorção do $\mathrm{K}$ pelos órgãos são do $10^{\circ}$ e $20^{\circ}$ graus, estas não têm ponto de inflexão, e teoricamente os cultivares não apresentam uma época de exigência máxima.

De acordo com os dados, constatou-se que todos os cultivares atingiram ponto de máxima referente a caùles aos 116 dias, e que as quantidades máximas nesses órgãos estão variando entre 359 e $610 \mathrm{mg}$ de $\mathrm{K}$, sendo que a maior extração registrou-se no cultivar Campinas (IAC2712) e a menor no cultivar SH-2. 
Tabela 13 - Valores de ponto de máxima, em dias, quantidade máxima em $\mathrm{mg}$ de $\mathrm{K}$ nos órgãos por planta e ponto de inflexão, em dias.

\begin{tabular}{|c|c|c|c|c|c|c|c|}
\hline \multirow{2}{*}{ Cultivar } & \multicolumn{3}{|c|}{$\begin{array}{c}\text { Ponto de máxima } \\
\text { (dias) }\end{array}$} & \multicolumn{3}{|c|}{$\begin{array}{l}\text { Quantidade máxima } \\
\text { (mg/planta) }\end{array}$} & \multirow{2}{*}{ Total } \\
\hline & caule & follha & fruto & caule & folha & fruto & \\
\hline $\begin{array}{l}\text { Campinas } \\
\text { (IAC-2712) }\end{array}$ & 196 & 196 & 216 & 610 & 580 & 435 & 1.625 \\
\hline $\begin{array}{l}\text { Camanducaia } \\
(\text { IAC-3530) }\end{array}$ & 196 & 196 & 216 & 495 & 528 & 486 & 1.023 \\
\hline $\begin{array}{l}\text { Monte Alegre } \\
\text { (IAC-3113) }\end{array}$ & 196 & 156 & 216 & 490 & 402 & 478 & 1.370 \\
\hline SH-2 & 196 & 196 & 208 & 359 & 341 & 188 & 888 \\
\hline
\end{tabular}

Nas folhas a extração máxima do nutriente está variando entre 341 e $520 \mathrm{mg}$ de $\mathrm{K}$, aparecendo o cultivar Monte Alegre ( IAC-3113) como o de maior eficiência na extração, atingindo o ponto de máxima aos 156 dias, enquanto os demais o excederam em 40 dias. Este fato chama a atenção uma vez que a absorção do $K$ pelas folhas nesse cultivar acompanhou a sua acumulação em matéria seca. Quanto à extração pelos frutos, as quantidades máximas variam entre 188 e $435 \mathrm{mg}$ de $\mathrm{K}$, sendo que cultivar SH-2 apresentou capacidade de extração, atingindo o seu ponto de máxima aos 208 dias, enquanto os demais só o atingiram aos 216 dias. A menor quantidade foi extraída pelo cultivar SH-2, e a maior pelo cultivar Campinas (IAC-2712) verificando-se o mesmo fenômeno com relação ao total extraído.

Os valores das extrações de $\mathrm{K}$ em $\mathrm{kg} / \mathrm{ha}$ por 150.000 plantas pelos órgãos dos cultivares foram os seguintes: caules - 54 a $92 \mathrm{~kg} / \mathrm{ha}$; folhas - 51 a $87 \mathrm{~kg} / \mathrm{ha}$ e frutos - 28 a $73 \mathrm{~kg} / \mathrm{ha}$.

Observa-se por esses dados que a maior parte do $\mathrm{K}$ é extraído pelos caules, vindo em seguida folhas e frutos. RAZUMNAYA (1973), afirmou que morangueiros produzindo $2.500 \mathrm{~kg} / \mathrm{ha}$ extrairam de 41 a $51 \mathrm{~kg}$ de $\mathrm{K} / \mathrm{ha}$.

Examinando-se os dados da Tabela 11, verifica-se que a concentração do $\mathrm{K}$ foi mais alta nos caules em todas as épocas, enquanto para folhas e frutos as concentrações de uma certa forma foram crescentes até aos 176 dias, sendo que os frutos apresentaram menores concentrações aos 216 dias, quando também as folhas passaram a mostrar valores mais baixos, o que demonstra o estado senescente da cultura. 
E provável que concentrações mais elevadas de $\mathrm{K}$ nos caules (pecíolo + coroa) ; tenham se verificado em vista dos pecíolos terem sido anexados às coroas para análise do K. JOHN et alii (1975) mencionam que para a maioria dos nutrientes analisados, as concentrações foram mais altas nas folhas do que nos peciolos, fato que concorda também com Ballinger e Mason (1960), John e Boyton (1959), todos citados por JOHN et alii (1975), excetuando-se Ballinger e Mason (1960) também mencionados por JOHN et alii (1975), que constataram ser os pecíolos superiores para a determinação do $\mathrm{K}$, o que parece de certa forma explicar a ocorrência de valores mais elevados da concentração de $\mathrm{K}$ nos caules, considerando-se que os pecíolos fornecem percentual superior do nutriente.

Nas folhas, concentrações de $\mathrm{K}$ estão variando entre 1,36 a $1,64 \%$ e de 1,08 a $1,73 \%$ na faixa dos 76 aos 116 dias que corresponde ao início dos estádios de afloração e frutificação, que concordam com os valores mencionados por BOULD (1964) para concentração de $\mathrm{K}$ em folhas recentemente maduras no estádio de florescimento e frutificação. BRADFIELD (1970) estudando níveis crescentes de $K$, menciona concentrações desse nutriente nas folhas no estádio de frutificação, variando entre 0,78 e $1,32 \%$ como se observa, os valores de concentração de $\mathrm{K}$ mencionados pelo autor são ligeiramente mais baixos do que as concentrações de $\mathrm{K}$ nas folhas aos 76 dias, no presente trabalho.

BOULD (1964), menciona que em ensaio de campo conduzido com - cultivar "climax", obteve um aumento médio anual (entre épocas) de 1,8 a 2,8 t/acre, quando a concentração de $\mathrm{K}$ nas folhas no estádio de frutificação se elevou a 0,88 para $1,48 \%$. BOULD (1964), frisa ainda uqe em um ensaio fatorial (NPK) com o cultivar "Royal Sovering", não obteve resposta à fertilização potássica na produção em duas épocas, quando a concentração de $\mathrm{K}$ nas folhas no estádio de frutificação era maior do que $1,5 \%$.

Como sugestões de padrões paradiagnose foliar são apresentadas as variações na concentração do $K$ nas folhas $(1,36$ a $1,69 \%)$ aos 76 dias e $(1,08$ a $1,73 \%)$ aos 116 dias, que correspondem aos estádios de floração e frutificação, quando as taxas de absorção de $\mathrm{K}$ foram mais altas.

\section{Cálcio}

Os valores da concentração e as quantidades de Ca nos órgãos dos cultivares acham-se expressos na Tabela 14.

Os valores de $\mathbf{F}$ das análises da variância conjunta (não incluída) das quantidades em $\mathrm{mg}$ de $\mathrm{Ca}$ nos órgãos dos cultivares revelou os seguintes resultados: 


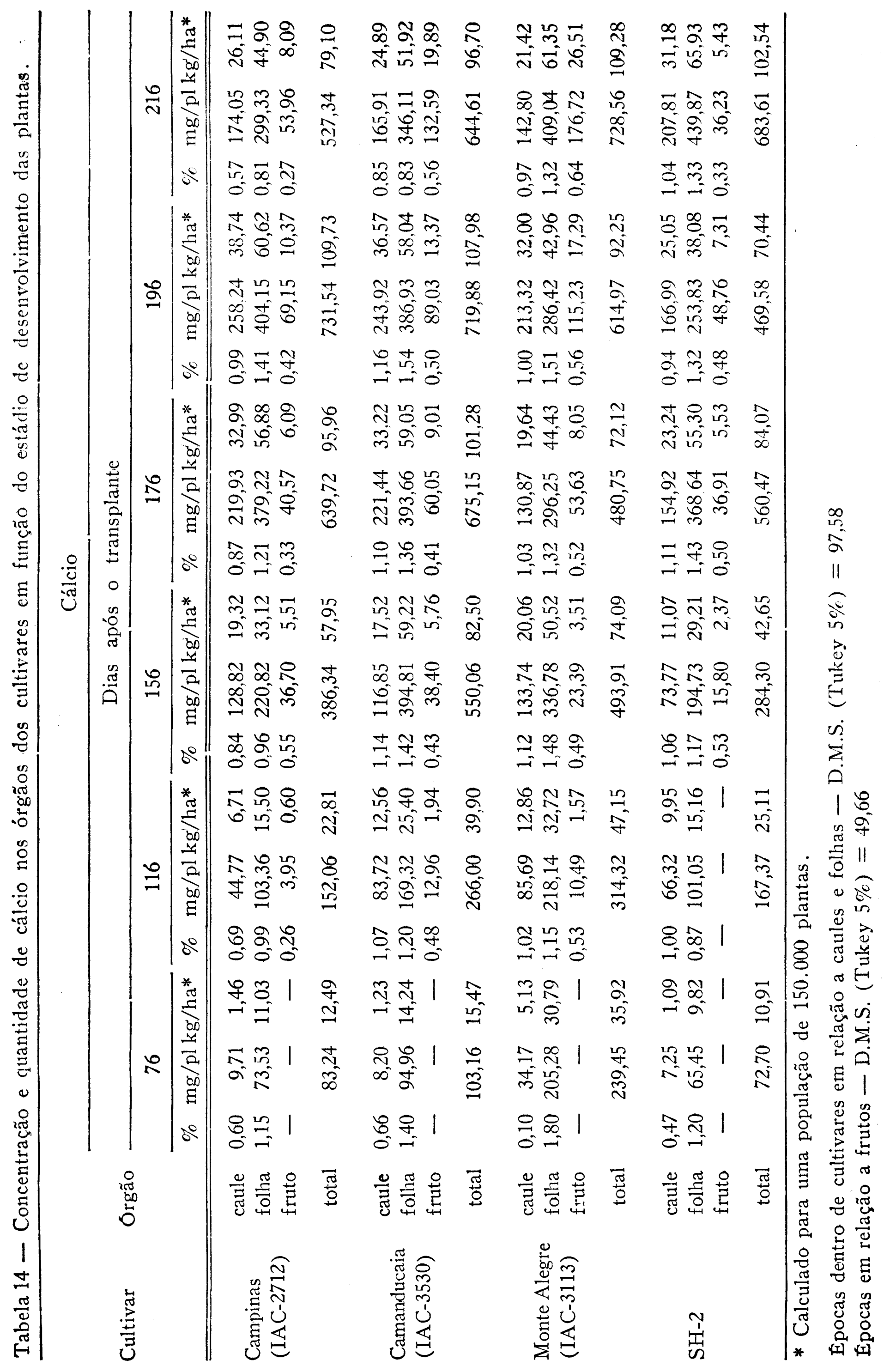


- os cultivares diferem na absorção de Ca para caules e folhas, não se verificando o mesmo em relação aos frutos.

- a interação de cultivares $\mathrm{x}$ épocas foi significativa em relação a caules e folhas revelando uma dependência entre cultivares e épocas de absorção de Ca.

- a análise da regressão indicou que as curvas que descrevem a absorção do Ca nos órgãos correspondem a regressões do $1 .^{\circ}$ e do $3 .^{\circ}$ graus e se encontram na Tabela 15.

Tabela 15 - Regressões representativas da absorção de cálcio pelos órgãos dos cultivares em $\mathrm{mg} /$ planta $(\hat{\mathrm{y}})$ em função da idade $(\mathrm{X})$ em dias após o transplante.

\begin{tabular}{|c|c|c|c|}
\hline \multirow[b]{2}{*}{ Cultivar } & \multicolumn{3}{|c|}{ Cálcio } \\
\hline & Órgão & Equação de regressão & $\begin{array}{l}\text { Coeficiente } \\
\text { de determi- } \\
\text { nação }\left(\mathrm{r}^{2}\right)\end{array}$ \\
\hline $\begin{array}{l}\text { Campinas } \\
\text { (IAC-2712) }\end{array}$ & $\begin{array}{l}\text { caule } \\
\text { folha } \\
\text { fruto }\end{array}$ & $\begin{array}{l}\hat{\mathrm{y}}=-171,694+2,074 X \\
\hat{\mathrm{y}}=-176,699+2,774 X \\
\hat{\mathrm{y}}=-165,194+1,233 \mathrm{X}\end{array}$ & $\begin{array}{l}0,93 \\
0,91 \\
0,98\end{array}$ \\
\hline $\begin{array}{l}\text { Camanducaia } \\
\text { (IAC-3530) }\end{array}$ & $\begin{array}{l}\text { caule } \\
\text { folha } \\
\text { fruto }\end{array}$ & $\begin{array}{l}\hat{\mathrm{y}}=-138,534+1,850 \mathrm{X} \\
\hat{\mathrm{y}}=1474,707-46,026 \mathrm{X}+39,568 \cdot 10^{-2} \mathrm{X}^{2}-10,012 \cdot 10^{-4 X^{3}} \\
\hat{\mathrm{y}}=-165,194+1,233 \mathrm{X}\end{array}$ & $\begin{array}{l}0,94 \\
0,99 \\
0,98\end{array}$ \\
\hline $\begin{array}{l}\text { Monte Alegre } \\
\text { (IAC-3113) }\end{array}$ & $\begin{array}{l}\text { caule } \\
\text { folha } \\
\text { fruto }\end{array}$ & $\begin{array}{l}\hat{y}=-82,345+1,463 X \\
\hat{y}=138,566+0,906 X \\
\hat{y}=-165,194+1,233 X\end{array}$ & $\begin{array}{l}0,98 \\
0,57 \\
0,98\end{array}$ \\
\hline $\mathrm{SH}-2$ & $\begin{array}{l}\text { caule } \\
\text { folha } \\
\text { fruto }\end{array}$ & $\begin{array}{l}\hat{y}=-96,897+1,216 X \\
\hat{y}=-70,226+1,646 X \\
\hat{y}=-165,194+1,233 X\end{array}$ & $\begin{array}{l}0,90 \\
0,97 \\
0,98\end{array}$ \\
\hline
\end{tabular}

Para todos os cultivares constatou-se que os caules apresentam comportamento linear na absorção do $\mathrm{Ca}$. Os cultivares Campinas (IAC-2712), Camanducaia (IAC-3530) e Monte Alegre (IAC-3113) apresentaram um ponto em comum em suas exigências em Ca aos 131 dias, com extração de $131,25 \mathrm{mg}$ de Ca que corresponde no global a $50 \%$ das quantidades máximas extraídas pelos caules e 25\% das quantidades máximas extraídas pelas folhas.

A absorção do Ca pelas folhas comportou-se segundo regressões do $1 .^{\circ}$ e do $3 .^{\circ}$ graus, destacando-se os cultivares Campinas (IAC-2712), 
Monte Alegre (IAC-3113) e SH-2 que absorveram linearmente o Ca, enquanto o cultivar Camanducaia (IAC-3530), adaptou-se ao comportamento curvilíneo (3. $\mathrm{grau})$, e para os frutos comportamento linear.

Com relação aos frutos constatou-se um comporamento linear na absorção do Ca como mostram os dados da Tabela 15.

Os pontos de máxima quantidade extraída e a época em que os cultivares apresentam maior exigência do nutriente são mostrados na Tabela 16. Pelos dados observa-se que todos os cultivares em relação

Tabela 16 - Valores de ponto de máxima em dias, quantidade máxima em $\mathrm{mg}$ de Ca nos órgãos por planta e ponto de inflexão em dias.

\begin{tabular}{|c|c|c|c|c|c|c|c|c|c|c|}
\hline \multirow{2}{*}{ Cultivar } & \multicolumn{3}{|c|}{$\begin{array}{l}\text { Ponto de Máxima } \\
\text { (dias) }\end{array}$} & \multicolumn{4}{|c|}{$\begin{array}{c}\text { Quantidade de Máxima } \\
(\mathrm{mg} / \mathrm{planta}\end{array}$} & \multicolumn{3}{|c|}{$\begin{array}{l}\text { Ponto de Inflexão } \\
\text { (dias) }\end{array}$} \\
\hline & caule & folha & fruto & caule & folha & fruto & total & caule & folha & fruto \\
\hline $\begin{array}{l}\text { Campinas } \\
\text { (IAC-2712) }\end{array}$ & 196 & 196 & 216 & 234 & 366 & 101 & 701 & - & 一 & - \\
\hline $\begin{array}{l}\text { Camanducaia } \\
\text { (IAC-3530) }\end{array}$ & 196 & 176 & 216 & 224 & 444 & 101 & 769 & - & 131 & - \\
\hline $\begin{array}{l}\text { Monte Alegre } \\
\text { (IAC-3113) }\end{array}$ & 196 & 196 & 216 & 204 & 315 & 101 & 620 & 一 & 一 & - \\
\hline SH-2 & 196 & 196 & 216 & 151 & 252 & 101 & 504 & - & - & - \\
\hline
\end{tabular}

aos caules atingiram o ponto de máxima aos 196 dias, com quantidades máximas entre os cultivares variando entre 151 e $324 \mathrm{mg}$ de Ca. Em relação às folhas, os valores de extração máxima estão variando de 252 a $444 \mathrm{mg}$ de Ca entre os cultivares, sendo mais precoces o cultivar Camanducaia (IAC-3530), que atinge o ponto de máxima extração aos 176 dias, enquanto os outros cultivares só o atingem aos 196 dias, este cultivar também apresenta uma época de maior exigência de nutriente em relação às folhas aos 131 dias. A extração máxima pelos frutos em média foi de $101 \mathrm{mg}$ de Ca para todos os cultivares com ponto de máxima aos 196 dias.

As quantidades de $\mathrm{Ca}$ extraídas pelos órgãos dos cultivares (150.000 plantas/ha) foram: caules - 23 a $35 \mathrm{~kg}$; folhas - 38 a $67 \mathrm{~kg}$ e frutos $15 \mathrm{~kg}$. Observa-se pelos dados que a maior extração do nutriente pelas folhas, foi maior do que aquela realizada pelos caules, e em menor proporção pelos frutos, o que parece indicar uma pequena mobilidade do Ca para os frutos. As quantidades de $\mathrm{Ca}$ extraídas pelos órgãos 
dos cultivares, são menores do que as extrações de $\mathbf{K}$, porém, as extrações de Ca são maiores do que as de P. Referências sobre extração do Ca por cultivares do morangueiro, não foram encontradas na literatura.

Concentrações de Ca nas folhas são mais elevadas na fase inicial de floração aos 76 dias, com intervalo de variação mais amplo variando de 1,15 a $1,80 \%$ como mostram os dados da Tabela 14 . JOHANSON e WALKER (1963), mencionam como níveis deficientes e adequados de Ca nas folhas valores de 0,38 a $1,9 \%{ }^{(7)}$. BOULD e CATLOW (1954), citam valores de concentração de Ca nas folhas no estádio de floração variando de 0,72 a $1,9 \%$. JOHN et alii (1975), mencionam também que as concentrações de $\mathrm{Ca}$ nas folhas foram mais elevadas no início do florescimento $(1,0$ a $0,95 \%)$ e no final do ciclo $(0,95$ a $1,07 \%)$. Nos caules as concentrações do nutriente se apresentaram mais altas na faixa dos 76 aos 166 dias, e decrescem aos 216 dias com variações entre 0,57 a $1,0 \%$ entre os cultivares.

As concentrações de Ca nos frutos de certa forma apresentam um comportamento semelhante ao dos caules, sendo que nos frutos as concentrações de Ca só aparecem a partir dos 116 dias, elevando-se até aos 196 dias, decrescendo aos 216 dias.

Como subsídio à aplicação da diagnose foliar, considera-se que aos 76 dias de idade, na época da floração, as folhas apresentam concentrção de Ca de 1,15 a $1,80 \%$.

\section{Magnésio}

As concentrações e as quantidades de $\mathrm{Mg}$ nos órgãos dos cultivares acham-se expressos na Tabela 17.

Os resultados da análise da variância conjunta (não incluída) mostraram os seguintes resultados:

- os cultivares não diferem significativamente na absorção do $\mathbf{M g}$ em relação a caules e folhas.

- não houve efeito significativo da interação cultivares $x$ épocas. Em vista disso, ajustou-se apenas uma equação de regressão expressando a absorção média do $\mathrm{Mg}$ por órgão para todos os cultivares como mostra a Tabela 18.

- os cultivares diferem na absorção do $\mathrm{Mg}$ em relação aos frutos.

- a interação cultivar $\mathrm{x}$ época em relação aos frutos foi significativa, mostrando uma dependência entre cultivares e épocas de absorção.

(7) Dados recalculados. 


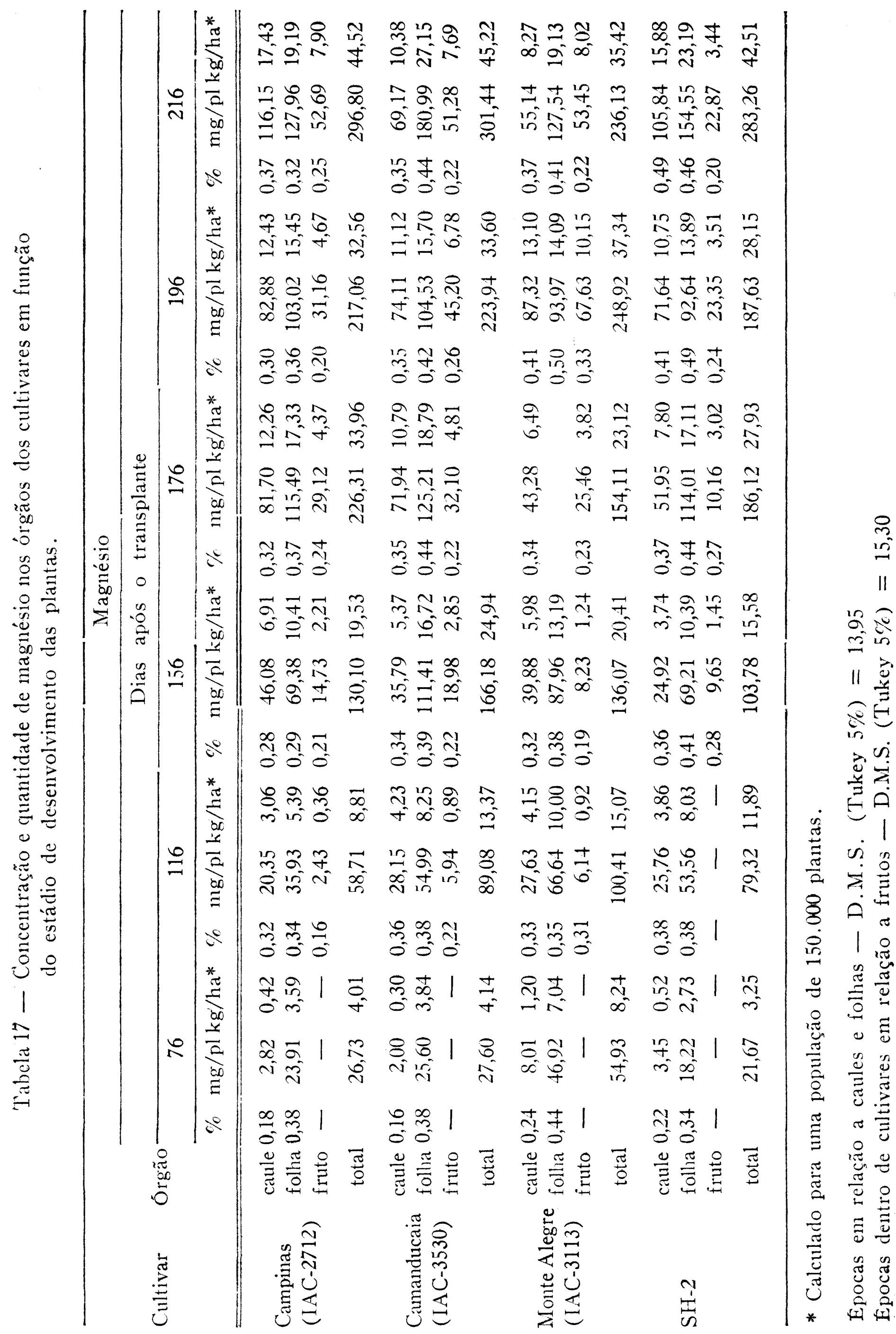


Tabela 18 - Valores de ponto de máxima em dias, quantidade máxima de $\mathrm{Mg}$ extraída em $\mathrm{mg}$ nos órgãos, por planta e ponto de inflexão em dias.

\begin{tabular}{|c|c|c|c|c|c|c|c|c|c|c|}
\hline \multirow{2}{*}{ Cultivar } & \multicolumn{3}{|c|}{$\begin{array}{l}\text { Ponto de Máxima } \\
\text { (dias) }\end{array}$} & \multicolumn{4}{|c|}{$\begin{array}{c}\text { Quantidade de Máxima } \\
\text { (mg/planta }\end{array}$} & \multicolumn{3}{|c|}{$\begin{array}{l}\text { Ponto de Inflexão } \\
\text { (dias) }\end{array}$} \\
\hline & caule & folha & fruto & caule & folha & fruto & total & caule & folha & fruto \\
\hline $\begin{array}{l}\text { Campinas } \\
\text { (IAC-2712) }\end{array}$ & 196 & 196 & 216 & 71 & 102 & 49 & 222 & 一 & - & - \\
\hline $\begin{array}{l}\text { Camanducaia } \\
\text { (IAC-3530) }\end{array}$ & 196 & 196 & 216 & 71 & 102 & 53 & 226 & - & - & - \\
\hline $\begin{array}{l}\text { Monte Alegre } \\
\text { (IAC-3113) }\end{array}$ & 196 & 196 & 203 & 71 & 102 & 73 & 246 & - & - & 182 \\
\hline SH-2 & 196 & 196 & 216 & 71 & 102 & 25 & 198 & - & - & - \\
\hline
\end{tabular}

Através das análises de regressão, procedeu-se o desdobramento das diferentes épocas dentro de cultivares em relação aos frutos.

As equações ajustadas para as curvas de absorção do $\mathrm{Mg}$ pelos frutos dos cultivares, encontram-se na Tabela 19. Excetuando-se o cultivar Camanducaia (IAC-3530), que se ajustou a uma equação do 3. ${ }^{\circ}$ grau, os demais se ajustaram a equações do $1 .^{\circ}$ grau.

O cultivar Monte Alegre (IAC-3113), apresentou em relação aos frutos, uma exigência maior do nutriente aos 182 dias, enquanto os demais cultivares teoricamente não o fizeram, pois, as curvas descrevem a absorção do nutriente para caules e folhas são do $1 .^{\circ}$ grau e não apresentam ponto de inflexão. Porém, observa-se que a época que se estende do crescimento inicial das plantas até aos 76 dias como mostram os dados da Tabela 17, parecem indicar que essa foi a faixa em que ocorreu uma maior demanda do nutriente pelos órgãos dos cultivares.

Os pontos de máxima extração, e a época em que os cultivares apresentam essa quantidade nos órgãos são apresentados na Tabela 18.

Verifica-se pelos dados que a extração máxima de $\mathrm{Mg}$ por caules e folhas foram as seguintes: $71 \mathrm{mg}$ e $102 \mathrm{mg}$ com ponto de máxima aos 196 dias. A extração do nutrientepelos frutos está variando entre os cultivares de 25 a $73 \mathrm{mg}$, com pontos de máxima entre 203 dias, sendo o cultivar Monte Alegre (IAC-3113) o mais precoce (203 dias) enquanto os demais cultivares só atingem após 13 dias. 
Tabela 19 - Regressões representativas da absorção média de magnésio (caules e folhas) pelos óagãos dos cultivares em $\mathrm{mg} /$ planta $(\hat{\mathrm{y}})$ em função da idade (X) em dias após o transplante.

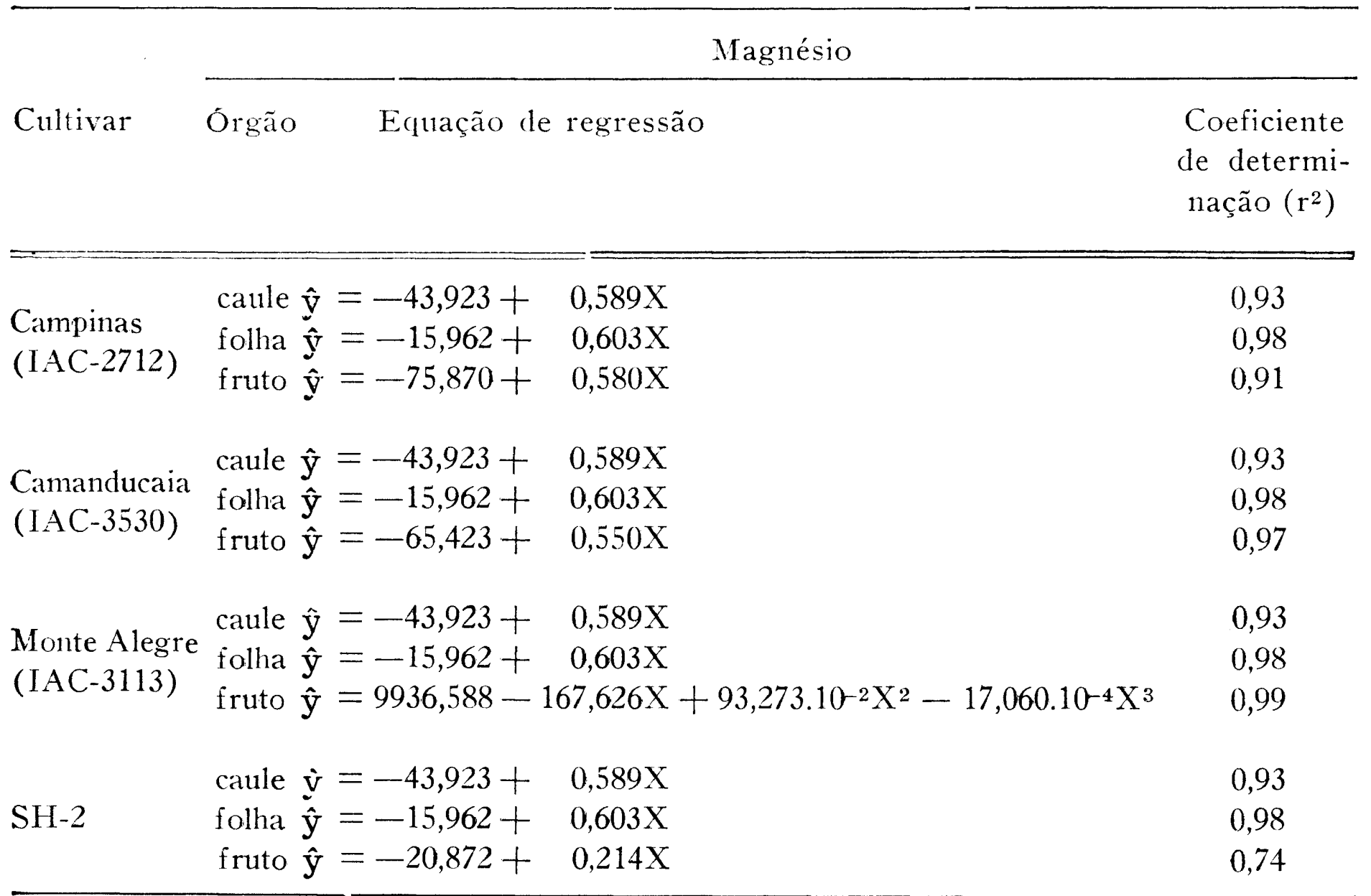

Citações sobre extração de $\mathrm{Mg}$ por cultivares de morangueiro não foram encontrados na literatura.

Os totais máximos de $\mathrm{Mg}$ em $\mathrm{kg} / \mathrm{ha}$ extraídos pelos cultivares variam de $30 \mathrm{~kg}$ a $37 \mathrm{~kg}$, enquanto a extração do nutriente pelos órgãos foi a seguinte: caules - $11 \mathrm{~kg} / \mathrm{ha}$; folhas $-15 \mathrm{~kg} / \mathrm{ha}$ e frutos $-4 \mathrm{a} 11 \mathrm{~kg} / \mathrm{ha}$. Comparando-se as extrações de $\mathrm{Mg}$ realizadas pelos órgãos dos cultivares com as quantidades extraídas de $\mathrm{N}, \mathrm{P}$ e $\mathrm{K}$, verifica-se que as exigências do morangueiro em $\mathrm{Mg}$ são bem menores. Este fato é mencionado por BOULD (1964), quando afirma que as exigências do morangueiro pelo Mg são relativamente baixas.

Com relação à concentração do nutriente nos órgãos, as folhas apresentam intervalos de variação mais amplos $(0,34-0,44 \%)$ entre 0 crescimento inicial das plantas até os 76 dias na floração e $(0,36-0,50 \%)$ aos 156 dias na frutificação.

Como indicação à diagnose foliar do morangueiro aos 76 dias, época de maior concentração de $\mathrm{Mg}$, apresenta uma faixa de 0,34 a $0,44 \%$. nas folhas e de 0,16 a $0,24 \%$ nos caules. 


\section{Enxofre}

As análises da variância conjunta (não incluída) mostraram os seguintes resultados:

- os cultivares não diferiram na absorção do $\mathbf{S}$ em relação a caules e folhas, tendo os mesmos diferido somente em relação a frutos.

- a interação cultivares x épocas foi significativa a $1 \%$ de probabilidade, tanto em relação a caules e folhas, como em relação a frutos, mostrando que existe uma dependência entre cultivares e épocas de absorção do nutriente. Procedeu-se o desdobramento através das análises de regressão das diferentes épocas dentro de cada cultivar.

A análise da regressão mostra que as curvas que descrevem a absorção de $\mathbf{S}$ nos órgãos dos cultivares correspondem a regressões do $1 .^{\circ}, 2 .^{\circ}$ e $3 .^{\circ}$ graus, e estão na Tabela 20.

Tabela 20 - Regressões representativas da absorção de enxofre pelos órgãos dos cultivares, em $\mathrm{m} g /$ planta $(\hat{\mathrm{y}})$, em função da idade $(\mathrm{X})$ em dias após o transplante.

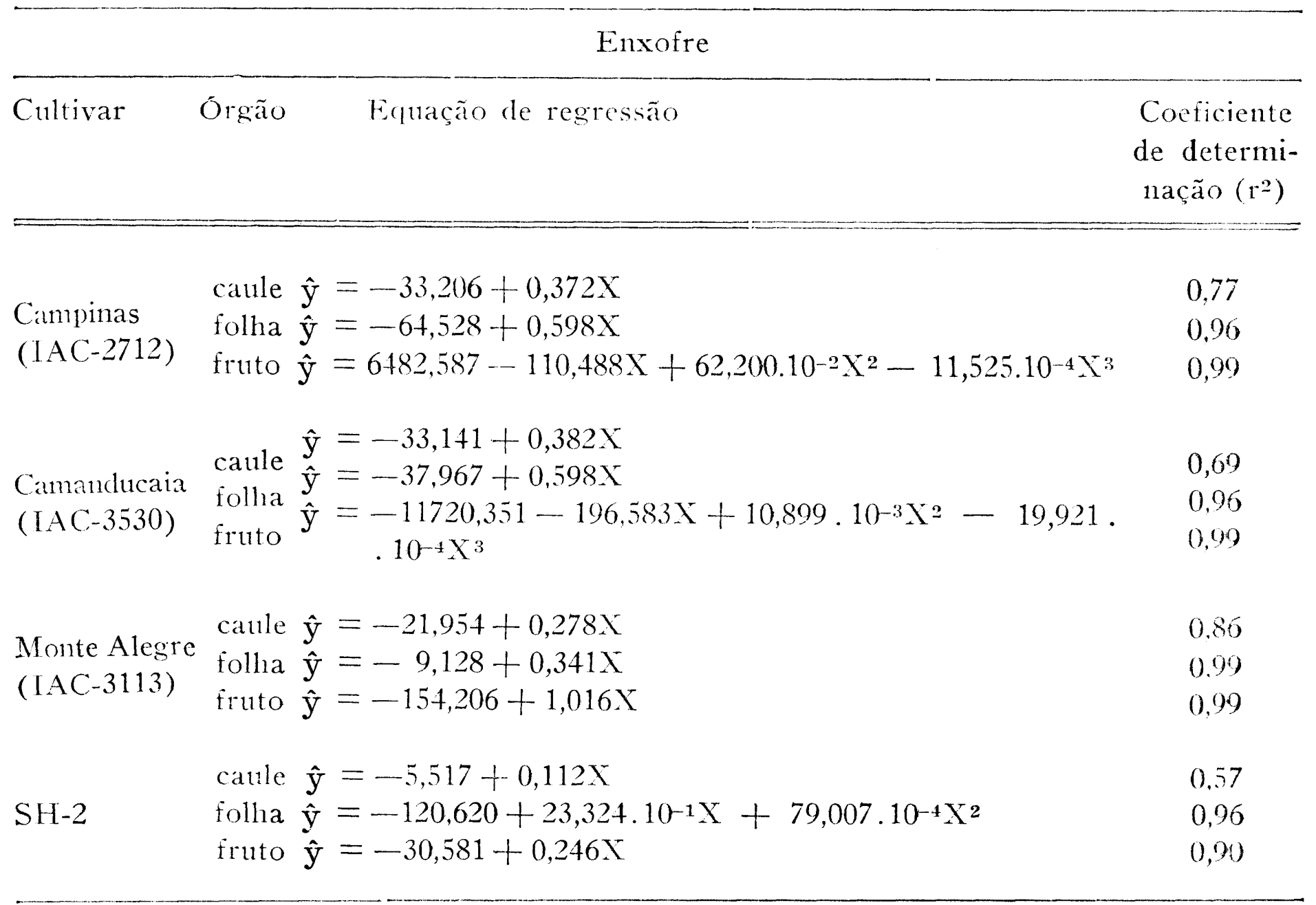


A absorção de $\mathbf{S}$ pelos caules em todos os cultivares adaptou-se uma regressão linear. A acumulação do $\mathrm{S}$ nas folhas pelos cultivares Campinas (IAC-2712), Camanducaia (IAC-3530) e Monte Alegre (IAC3113), também seguem comportamento linear, enquanto a absorção pelo cultivar SH-2 é curvilíneo (Tabela 19).

A absorção do $\mathrm{S}$ pelos frutos nos cultivares Campinas (IAC-2712), Camanducaia (IAC-3530), adaptam-se ao comportamento curvilíneo enquanto os cultivares Monte Alegre (IAC-3113) e SH-2 comportam-se de modo linear.

A extração máxima de $\mathbf{S}$ pelos órgãos dos cultivares e a época em que se deu esse fenômeno, são mostrados na Tabela 21.

Tabela 21 - Valores de ponto de máxima em dias, quantidade de máxima de S extraída em $\mathrm{mg}$ nos órgãos por planta e ponto de inflexão em dias.

\begin{tabular}{|c|c|c|c|c|c|c|c|c|c|c|}
\hline \multirow[t]{2}{*}{ Cultivar } & \multicolumn{3}{|c|}{$\begin{array}{c}\text { Ponto de Máxima } \\
\text { (dias) }\end{array}$} & \multicolumn{4}{|c|}{$\begin{array}{c}\text { Quantidade Máxima } \\
\text { (mg/planta) }\end{array}$} & \multicolumn{3}{|c|}{$\begin{array}{l}\text { Ponto de Inflexão } \\
\text { (dias) }\end{array}$} \\
\hline & caule & folha & fruto & caule & folha & fruto & total & caule & follia & fruto \\
\hline $\begin{array}{l}\text { Campinas } \\
\text { (IAC-2712) }\end{array}$ & 196 & 196 & 199 & 39 & 92 & 44 & 175 & - & - & 179 \\
\hline $\begin{array}{l}\text { Camanducaia } \\
\text { (IAC-3530) }\end{array}$ & 196 & 196 & 201 & 41 & 79 & 59 & 179 & - & - & 182 \\
\hline $\begin{array}{l}\text { Monte Alegre } \\
\text { (IAC-3113) }\end{array}$ & 196 & 196 & 216 & 32 & 57 & 65 & 154 & - & - & - \\
\hline $\mathrm{SH}-2$ & 196 & 147 & 216 & 16 & 51 & 22 & 89 & - & - & - \\
\hline
\end{tabular}

As quantidades extraídas pelos órgãos variam de 16 a $41 \mathrm{mg}$ nos caules, nas folhas de 51 a $92 \mathrm{mg}$ e nos frutos de 22 a $65 \mathrm{mg}$. Os pontos de máxima em relação aos caules em todos os cultivares cumprem-se aos 196 dias, para folhas, esses valores variam entre os 147 e os 196 dias, destacando-se o cultivar $\mathrm{SH}-2$ como o mais precoce, e os demais tadios. Nos frutos, o intervalo de variação para pontos de máxima vão dos 199 aos 216 dias, sobressaindo-se os cultivares Campinas (IAC-2712) e Camanducaia (IAC-3530) por serem os mais precoces, atingindo a época de maior exigência pelo $\mathrm{S}$ aos 179 dias e aos 182 dias.

A partir dos totais extraídos pelos cultivares, observa-se que a menor extração $(13 \mathrm{~kg} / \mathrm{ha})$ é realizada pelo cultivar $\mathrm{SH}-2$ e a maior 


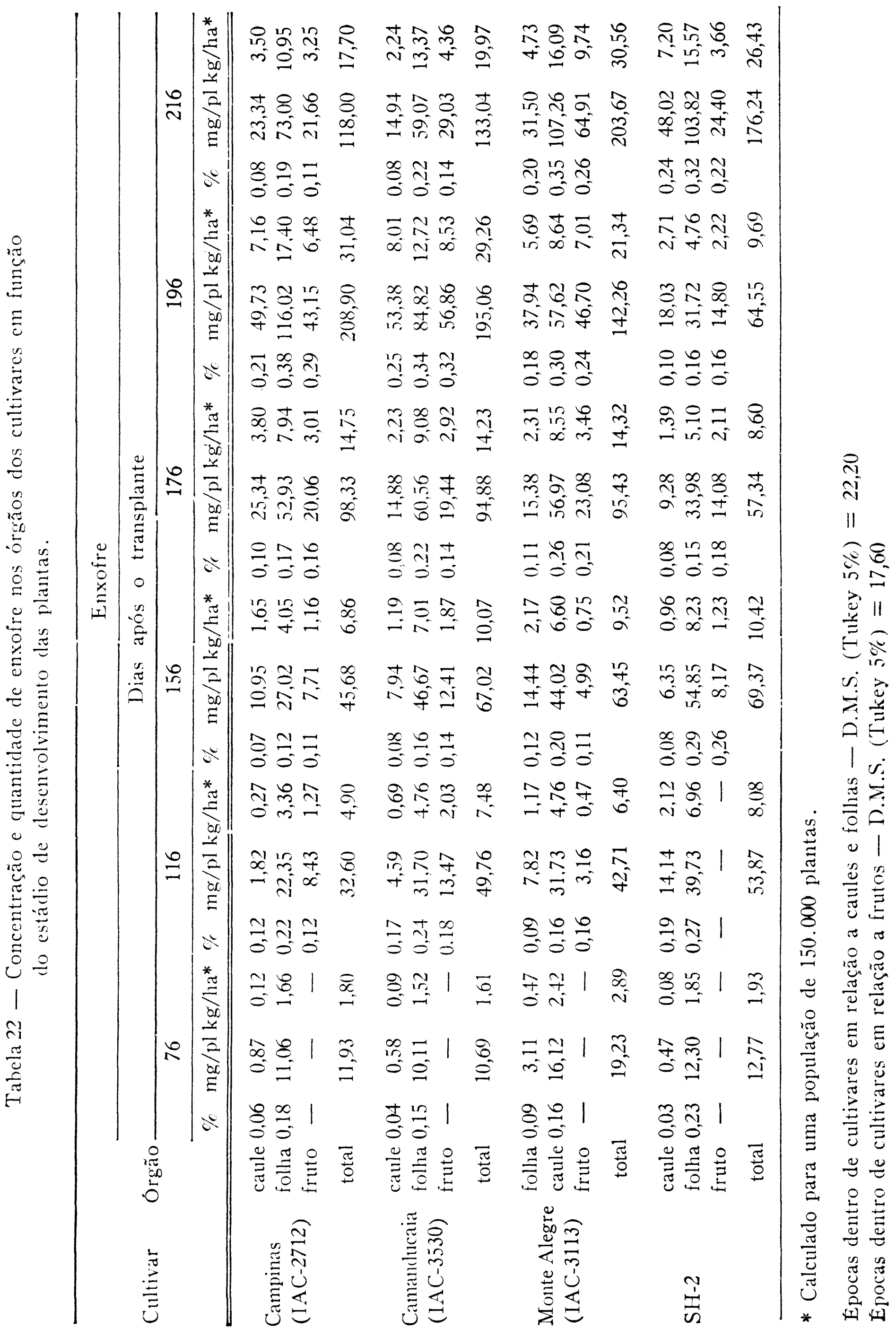


(27 kg/ha) pelo cultivar Camanducaia (IAC-3530). As extrações de S pelos órgãos, obedecem à seguinte ordem: folhas (8 a $14 \mathrm{~kg}$ ), frutos ( 3 a $9 \mathrm{~kg}$ ) e caules (2 a $9 \mathrm{~kg}$ ). Confrontando-se as quantidades de $\mathrm{S}$ extraídas pelos órgãos dos cultivares com as extraídas de $\mathrm{N}, \mathrm{P}, \mathrm{K}, \mathrm{Ca}$ e $\mathrm{Mg}$, constata-se que no conjunto, as exigências em $\mathbf{S}$ entre os cultivares são menores do que as exigências por esses nutrientes. Dados referentes à extração do $\mathbf{S}$ por cultivares de morangueiro, não foram encontrados na literatura.

Os valores da concentração e as quantidades de $\mathrm{S}$ nos órgãos dos cultivares acham-se expressos na Tabela 22.

Observando-se os dados da concentração (Tabela 22) nos órgãos, verifica-se que o teor percentual do nutriente é mais elevado em: folhas, frutos e caules. Nas folhas e nos caules esses valores tendem a decrescer quando se intensifica a frutificação, com exceção dos cultivares Monte Alegre (IAC-3113) e SH-2 que apresentam maior estabilidade na concentração até aos 216 dias após o transplante. Este fato está de acordo com JOHN et alii (1975) quando menciona que a concentração do S decresceu rapidamente nos pecíolos e nas folhas durante a floração e frutificação, estando ainda de acordo com este autor os dados da concentração encontrados nos demais órgãos dos cultivares. Nos frutos, a concentração do $\mathbf{S}$ no global apresenta valores crescentes até aos 196 dias, com exceção dos cultivares Monte Alegre (IAC-3113) e SH-2 que se sobressaem entre os demais com 0,26 e $0,22 \%$ de $\mathrm{S}$ nos frutos aos 216 dias, o que parece refletir até certo ponto o comportamento linear do conteúdo de $\mathbf{S}$ nos frutos desses cultivares.

Para efeito de diagnose foliar apresentamos as variações nas concentrações encontradas nas folhas $(0,15$ a $0,23 \%)$ e nos caules $(0,03$ a $0,09 \%$ ) aos 76 dias após o transplante por corresponder ao estádio de floração, época em que as taxas de absorção do nutriente são mais elevadas.

\section{CONCLUSÕES}

- Os cultivares diferem na produção de matéria seca, tanto em relação a caules e folhas, como em relação a frutos.

- A produção de matéria seca nos caules e nos frutos foi linear para todos os cultivares, até a última amostragem aos 196 dias e aos 216 dias, com produções máximas variando entre 15 a 25 g e 12 a 20 g nesses órgãos por planta, respectivamente.

- A produção máxima de matéria seca nas folhas entre os cultivares variou entre 20 e $30 \mathrm{~g}$ com a idade de196 e 173 dias. 
- A maior produção de matéria seca tanto nos órgãos como na planta inteira, ocorreu nos cultivares Campinas (IAC-2712) e Camanducaia (IAC-3530) e a menor produção verificou-se no cultivar SH-2.

- Os cultivares diferem na absorção dos nutrientes: $\mathrm{P}, \mathrm{K}, \mathrm{Ca}$, $\mathrm{S}$ para caules e folhas. E para frutos, N, P, K, Mg e S.

- Os cultivares atingem o máximo da absorção de nutrientes nos órgãos nas seguintes épocas, em dias:

\begin{tabular}{cccc}
\hline Nutriente & caule & folha & fruto \\
\hline \hline $\mathrm{N}$ & 196 & 176 & 216 \\
$\mathrm{P}$ & 196 & $194-196$ & 213 \\
$\mathrm{~K}$ & 196 & $156-196$ & $208-216$ \\
$\mathrm{Ca}$ & 196 & $176-196$ & 216 \\
$\mathrm{Mg}$ & 196 & 196 & $203-216$ \\
$\mathrm{~S}$ & 196 & $147-196$ & $199-216$ \\
\hline
\end{tabular}

$\mathrm{Ca}$ e $\mathrm{Mg}$.

- Tanto os macronutrientes são extraídos em quantidades mais elevadas através das folhas e em menor proporção por caules e frutos.

- As extrações de $\mathrm{N}, \mathrm{K}$ e Ca são mais altas que aquelas dos demais macronutrientes.

- As extrações de $\mathrm{P}$ pelos cultivares são menores que as de $\mathrm{Ca}$ e $\mathrm{Mg}$, sendo ainda as extrações de $\mathrm{Ca}$ superiores às de $\mathrm{Mg}$, enquanto no global as de $\mathrm{Mg}$ são equivalentes às de $\mathrm{S}$.

- A extração de macronutrientes verifica-se na ordem decrescente: $\mathrm{K}, \mathrm{N}, \mathrm{Ca}, \mathrm{Mg}, \mathrm{S}$ e $\mathrm{P}$.

SUMMARY

MINERAL NUTRITION OF VEGETABLE CROPS. XXIX. ABSORPTION OF NUTRIENTS BY FOUR STRAWBERRY (FRAGARIA SPP) CULTIVARS

The aim of this work was to estimate the differences in growth (dry weight basis), nutrients uptake, fruits yield, total uptake and exportation of nutrients among several strawberry cultivars: Campinas (IAC-2712), Camanducaia (IAC-3530), Monte Alegre 
(IAC-3113) and SH-2. The experimental was carried out in the Escola Superior de Agricultura "Luiz de Queiroz", in field conditions, in 1975/76. The soil belongs to Terra Roxa Estruturada type, and "Luiz de Queiroz" serie. This soil has been cultivated for more than 25 years. The experimental design was that randomized blocks with four replications and analysed together following the design of split-plot.

The soil of the plots were revolved to a deep of $12 \mathrm{~cm}$ following application of $10 \mathrm{~kg}$ organic matter $/ \mathrm{m}^{2}$. The fertilizers were applied in the groove and in the same amount for all cultivars: Ammonium sulfate $(20 \% \mathrm{~N}), 10 \mathrm{~g} / \mathrm{m}$; triple superphosphate $\left(20 \% \mathrm{P}_{2} \mathrm{O}_{5}\right)$ $10 \mathrm{~g} / \mathrm{m}$; Potassium cloride $\left(60 \% \mathrm{~K}_{2} \mathrm{O}\right), 10 \mathrm{~g} / \mathrm{m}$. Therty days after planting, $10 \mathrm{~g} /$ plant of ammonium sulfate was applied. After 76 days from planting, the firsa sample was taken. Other samples were taken in equal intervals of 20 days, up to 216 days. When a decrease in fruitproduction was noted. The sample (plants) were divided in stems, leaves and fruits and chemical analysis were made for $\mathrm{N}, \mathrm{P}, \mathrm{K}, \mathrm{Ca}, \mathrm{Mg}$ e $\mathrm{S}$. The variation on production (dry matter) nutrient uptake and fruits yieldi, were obtained from data calculated by adjusted regression equation analysis. The maxima point from these equations were taken to show the total nutrient uptake. From the data obtained, the following conclusions could be drawn.

Growth - The dry matter of stems, leaves and fruits were different among the cultivars. The production of dry matter by the stems and fruits were linnear for all cultivars up to 196 and 216 days. The highest productions on dry matter varied between 15 to $25 \mathrm{~g}$ and 12 to $20 \mathrm{~g} /$ plant. The maximum production of dry matter in the leaves among the cultivars varied between 20 to $30 \mathrm{~g}$ at 196 and 173 days respectivelly. The cultivars Campinas (IAC-2712) and Camanducaia (IAC-3530) produced more dry matter than SH-2 cultivar. Nutrient uptake - The were differences on nutrient content in stems and leaves among cultivars $(\mathrm{P}, \mathrm{K}, \mathrm{Ca}, \mathrm{S}, \mathrm{B})$ and in the fruits for $\mathrm{N}, \mathrm{P}, \mathrm{K}, \mathrm{Mg}, \mathrm{S}$. The highest absorption of nutrients (days after planting) is shown in Table $\mathrm{I}$.

\section{Table I}

\begin{tabular}{|c|c|c|c|}
\hline Nutrients & stems & leaves & fruit \\
\hline & & days & \\
\hline $\mathrm{N}$ & 196 & 176 & 216 \\
\hline$P$ & 196 & $194-196$ & 213 \\
\hline $\mathrm{K}$ & 196 & $156-196$ & $208-216$ \\
\hline $\mathrm{Ca}$ & 196 & 176-196 & 216 \\
\hline $\mathrm{Mg}$ & 196 & 196 & $203-216$ \\
\hline $\mathrm{S}$ & 196 & $147-196$ & $199-216$ \\
\hline
\end{tabular}

Yield - No significant difference in fruit production was observed among the cultivars. The highest yield among the cultivars showed a variation between 103 to $151 \mathrm{~g}$ per plant at the 207 and 207 days. 
Nutrient uptake and exportation - The uptake and export of nutrients were different among the cultivars. However no difference was found for $\mathrm{N}$. The highest accumulation of macro are found in the leaves. The following decrescent order of macronutrients uptake was found $\mathrm{K}>\mathrm{N}>\mathrm{Ca} \geqslant \mathrm{Mg}=\mathrm{S}>\mathrm{P}$. The nutrient exportation by the frnits are lowers than the amount of nutrients retained by the stems and leaves (Table II).

The maximum quantities of nutrients absorved, in $\mathrm{kg} / \mathrm{ha} *$, by the cultivars were:

Table II

\begin{tabular}{|c|c|c|c|c|c|c|c|}
\hline \multirow[b]{2}{*}{ Cultivar } & \multirow[b]{2}{*}{ Plant part } & \multicolumn{6}{|c|}{ Nutrient } \\
\hline & & $\mathrm{N}$ & $\mathrm{P}$ & $\mathrm{K}$ & $\mathrm{Ca}$ & $\mathrm{Mg}$ & $\mathrm{S}$ \\
\hline \multirow{4}{*}{$\begin{array}{l}\text { Campinas } \\
\text { (IAC-2712) }\end{array}$} & stems & 35 & 21 & 92 & 35 & 11 & 6 \\
\hline & leaves & 92 & 20 & 87 & 55 & 15 & 14 \\
\hline & fruits & 65 & 9 & 65 & 15 & 7 & 7 \\
\hline & total & 192 & 50 & 244 & 105 & 33 & 27 \\
\hline \multirow{4}{*}{$\begin{array}{l}\text { Camanducaia } \\
\text { (IAC-3530) }\end{array}$} & stems & 35 & 9 & 74 & 34 & 11 & 6 \\
\hline & leaves & 92 & 18 & 79 & 67 & 15 & 12 \\
\hline & fruits & 65 & 9 & 73 & 15 & 8 & 9 \\
\hline & total & 192 & 36 & 226 & 116 & 34 & 27 \\
\hline \multirow{3}{*}{$\begin{array}{l}\text { Monte Alegre } \\
\text { (IAC-3113) }\end{array}$} & stems & 35 & 8 & 73 & 31 & 11 & 9 \\
\hline & leaves & 92 & 16 & 60 & 47 & 15 & 10 \\
\hline & fruits & 65 & 9 & 72 & 15 & 11 & 5 \\
\hline \multirow{5}{*}{ SH-2 } & total & 192 & 33 & 205 & 93 & 37 & 24 \\
\hline & stems & 35 & 6 & 54 & 23 & 11 & 2 \\
\hline & leaves & 92 & 9 & 51 & 38 & 15 & 8 \\
\hline & fruits & 65 & 9 & 28 & 15 & 4 & 3 \\
\hline & total & 192 & 24 & 133 & 76 & 30 & 13 \\
\hline
\end{tabular}

* Plant population - 150,000 plants. 


\section{LITERATURA CITADA}

ANDERSON, J.F., J.S. BAILEY, DRAKE, MACK e G.W. OLANYK. 1963. Mineral Content of Strawberry Leaves as Influenced by Rate an Placement of Fertilizer and Lime. Proceedings of the American Society for Horticultural Science, St. Josph, Michigan, 85: 332-337.

ANDRADE, A.C. 1975. Acumulação Diferencial de Nutrientes por Cinco Cultivares de Milho (Zea mays L.). Piracicaba, ESALQ, USP. 92 p. (Dissertação de Mestrado).

BOULD, C. e E. CATLOW. 1954. Manurial Experiments With Fruit. I - The Effect of Long. term Manurial Treatments on Soil Fertility and on the Grow, Yield and Leaf Nutrient Status of Strawberry, var. climax. Journal of Horticultural Science, Lonon, 29 : 203-209.

BOULD, C. 1964. Leaf Analysis as a Guide to the Nutrition of Fruit Crops. V - Sand Culture N, P, K, Mg Experiments With Strawberry (Fragaria spp.). Journal of Science Food and Agriculture, London, 15: 474-487.

BOYCE, B.R. e D.L. MATLOCK. 1966. Strawberry Nutrition. In: Chieldrs, N.F. ed. Nutrition of Fruit Crops. 2 ed. New Brunswick. p. 518-548.

BRADFIELD, E.G. 1975. Potassium Nutrition of the Strawberry Plant. I - Rates of Dry Matter Production and Potassium Uptake. Effect of Potassium Suppley on Components of Yield. Journal of Science Food and Agriculture, London, 21: 554-558.

BRADFIELD, E.G., B. DAMANIOS e J.F. STICKLAND. 1975. Plassium Nutrition of Strawberry Plant. Effect of Potassium Treatment and of the Rooting Media on Components of Yield Land Crytical Leaf Potassium Concentration. Journal of Science Food and Agriculture, London, 26: 669-674.

CAMARGO, L.S. de, BERNARDI, S.B., S. ALVES e E. ABRAMIDES. 1973. Comportamento de Novas Variedades Híbridas de Morangueiro, em Monte Alegre do Sul, no ano de 1968. Bragantia, Campinas, 27: 165-167.

CAMARGO, L.S. de. 1973. Instrução para a cultura do morangueiro. Boletim do Instituto Agronômico, Campinas, n.o 29. 32 p.

CAMARgO, P.N. 1970. Princípios de nutrição foliar. Piracicaba. Ed. Agronômica Ceres. $118 \mathrm{p}$.

CARBONARI, R. 1973. Influência da época de plantio na produção de algumas variedades de morangueiro (Fragaria spp.). Botucatu, Fac. de Ciênc. Méd. e Biológicas de Botucatu. 123 p. (Tese de Doutoramento).

CATANI, R.A. e A.O. JACINTHO. 1974 Avaliação da fertilidade do solo: Métodos de análises. Piracicaba, Livroceres. $61 \mathrm{p}$.

COMISSÃO DE SOLOS. 1960. Levantamento de reconhecimento dos solos do Estado de São Paulo. Boletim do Serviço Nacional dé Pesquisas Agronômicas, Rio de Janeiro, n. ${ }^{\circ} 12.634 \mathrm{p}$.

COSTA, M.C.B. H.P. HAAG e J.R. SARRUGE. 1972. Nutrição Mineral de Hortaliças. Absorção de macro e micronutrientes pela cultura do quiabeiro (Hibiscus esculentos L.). Anais da E.S.A. "Luiz de Queiroz", 29: 109-126.

ESCOLA SUPERIOR DE AGRICULTURA "LUIZ DE QUEIROZ". Departamento de Física e Meteorologia. 1973. Análise dos dados metereológicos de Piracicaba-SP. de 1917 a 1970. Boletim Técnico-Científico da ES $A L Q$, Piracicaba, n. ${ }^{\circ} 36.26$ p. 
FERNANDES, P.D. e H.P. HAAG. 1972. Nutrição Mineral de Hortaliças. XXI. Efeito da omissão dos macronutrientes no crescimento e na composição química do pimentão (Capsicum annum L.) cour. Avelar. Anais dia E.S.A. "Luiz de Qucirow", Piracicaba, $29: 223-235$.

FILGUEIRA, F.A.R. 1972. Manual de Olericultura: Cultura e Comercialiáação de Hortaliças. São Paulo, Ed. Agronômica Ceres. $451 \mathrm{p}$.

HAAG, H.P., G.D. de OLIVEIRA, BORDUCCHI, A.S. e J.R. SARRUGE. 1973. Absorção de nutrientes por duas variedades de maracujá. Anais da E.S.A.. "Luiz de Queiroz", Piracicaba,, 30: 267-279.

HAAG, H.P., G.D. de OLIVEIRA, S. WATANABE e J.R. SARRUGE. 1974. Nutrição Mineral das Plantas Ornamentais. III. Absorção de nutrientes pela rainha margarida (Callestephus chinensis). Anais da E.S.A. "Luiz de Queiroz", Piracicabal, 31 : Content in Strawberry Leaves. Rocsimiki Wyssy Poluiczy, n. ${ }^{\circ} 44: 77181$. Apud 223-332.

HOLUBOWICZ, F. 1969. Changes in Nitrogen, Phosphorus, Potassium and Calcium Horticultural Abstracts, London, 42 : 742.

INSTITUTO BRASILEIRO DE GEOGRAFIA E ESTATISTICA. 1957. Enciclopídia dos Municípios Brasileiros. Rio de Janeiro. V. 29.

JOHANSON, F.D. e R.B. WALKER. 1963. Nutrient Deficiences and Foliar Composition of Strawberryes. Proceedings of the American Society for Horticultural Science. St. Joseph, Michigan, 83: 431-439.

JOHN, M.K., H.A. DAUBNEY e F.D. Mc ELROY. 1975. Influence of Sampling Time on Elemental Composition of Strawberry Leaves and Petioles. Journal of the American Society for Horticultural Science. St. Joseph, Michigan, 100: 513-517.

LINEBERRY, R.A. e V. BURKHART. 1943. Nutrient Deficiences in the Strawberry Leaf and Fruit. Plant Physiology, New York, 18: 324-333.

MACEDO, M.C.M. 1976. Absorção de nutrientes por cultivares nacionais de batatinha (Solanum tuberosum L.). Piracicaba, ESALQ, USP. 97 p. (Dissertação de Mestrado).

MEYER, B.S., D.B. ANDERSON, e R.H. BÖHNING. 1970. Introdução à fisiologia vegetal. Fund. Calouste Gulbenkian. Lisboa. 563 p.

PIMENTEL GOMES, F. 1966. Curso de Esetatística Experimental. 3 ed. São Paulo, $404 \mathrm{p}$.

RANZANI, G., O. FREIRE e T. KINJO. 1966. Carta de Solos no município de Piracicaba, ESALQ, USP. 85 p.

RAZUMNAYA, E.D. 1975. Distribution of Nutrients and Their Removal by Strawberry Plants. Agrokhimiya, 5: 95-101. 1973. Apud Horticultural Abstracts, East Mailing, In. $45(2): 218$.

SARRUGE, J.R., GOMES, L., H.P. HAAG e E. MALAVOLTA. 1963. Estudos sobre a alimentação mineral do algodoeiro. I. Marcha de absorção de macronutrientes. Anais da E.S.A. “Luiz de Queiroz", Piracicaba, 20 : 13-23.

SARRUGE, J.R. e H.P. HAAG. 1974. Análise Química em Plantas. Piracicaba, ESALQ, USP. 56 p.

SETZER, J. 1946. Contribuição para o estudo do clima do Estado de São Paulo. São Paulo, Escolas Professores Salesianos. 239 p. 
SOUZA, A.F. 1976. Absorção de nutrientes por quatro cultivares de morangueiro (Fragaria $s p p$.$) . Piracicaba, ESALQ, USP 144$ p. (Dissertação de Mestrado).

THOMAZ, M.C. 1975. Nutrição mineral do espinafre (Tetragonia expansa Murr). Piracicaba, ESALQ, USP. 81 p. (Dissertação de Mestrado).

WEBB, R.A. e D.G. HALLAS. 1966. The effect of iron supply on strawberry, var. Royal Sovereign. Journal of Horticultural Science, 41: 179-188. 
